\title{
DIGITALLY CONTROLLED, MODULAR ELECTRONIC LOAD
}

\author{
A Master's Thesis \\ presented to \\ The Faculty of California Polytechnic State University,
}

San Luis Obispo

\author{
In Partial Fulfillment \\ Of the Requirements for the Degree \\ Master of Science in Electrical Engineering
}

By

Jason March

December, 2011 
(C) 2011

Jason March

ALL RIGHTS RESERVED 


\section{COMMITTEE MEMBERSHIP}

TITLE:

AUTHOR:

DATE SUBMITTED:

COMMITTEE CHAIR: Taufik

COMMITTEE MEMBER: Vladimir Prodanov

COMMITTEE MEMBER: Tina Smilkstein
Digitally Controlled, Modular Electronic Load

Jason March

December, 2011 


\section{ABSTRACT \\ Digitally Controlled, Modular Electronic Load \\ Jason March}

This project entails the design and development of a digitally controlled, modular electronic load. The proposed load is unique from existing designs because it has the added ability to increase its maximum current level by adding identical modules in parallel. Each module is designed to sink a maximum of $5 \mathrm{~A}$ at $60 \mathrm{~V}$ but more modules allow for more current. The cost and simplicity of the design are considered such that it can be reproduced in-house to replace, whenever possible, the resistor box for load testing of any analog circuits but more specifically power electronic circuits.

The design process as well as the hardware development is explained in detail in this report. Results from hardware testing are also provided.

Keywords: electronic load, power electronics, electronics, power resistor, micro-controller 


\section{ACKNOWLEDGEMENTS}

I would like to thank:

Jonathan Paolucci for the use of his design and the help and encouragement he gave me while building and testing this project. He spent countless hours giving me advice and working through some of the issues that were keeping this project from getting off the ground.

Scott McClusky, for his advice and wisdom while designing this project. Any questions I had during the design of the protection circuitry I was able to ask Scott and he provided me with design ideas and practical knowledge that I did not have.

Dr. Taufik for his support and help with this project and the countless hours he devoted to reading and editing this report. I would like to thank him for his inspiration and encouragement to take on this project. Also for his wonderful teaching that gave me the knowledge needed when working on and troubleshooting this project. 


\section{TABLE OF CONTENTS}

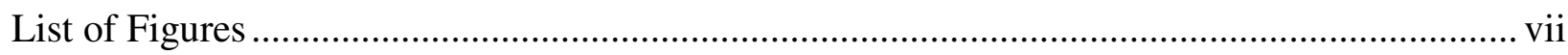

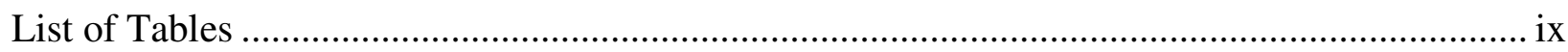

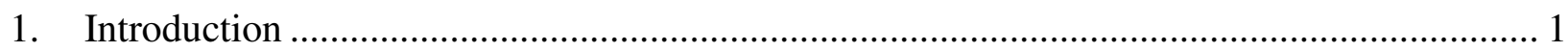

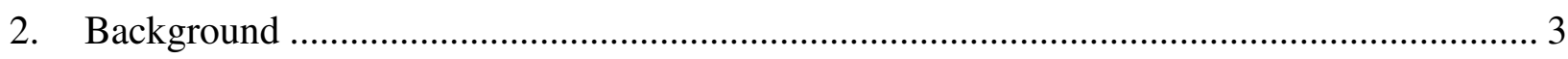

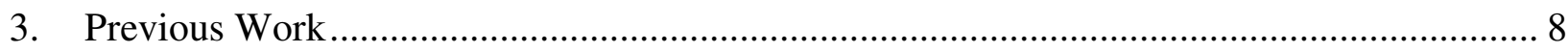

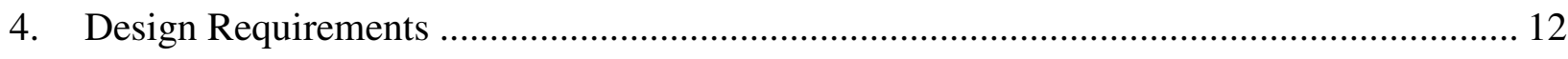

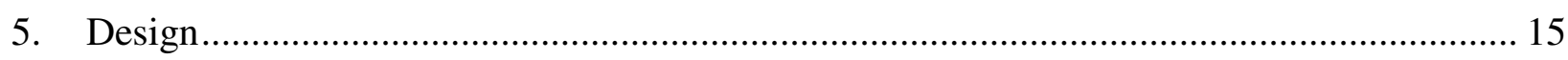

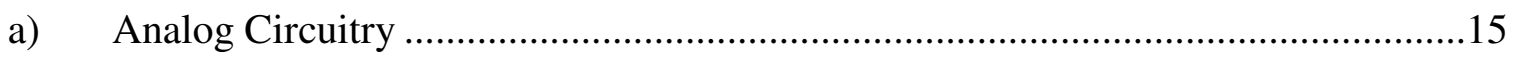

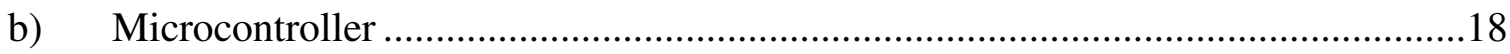

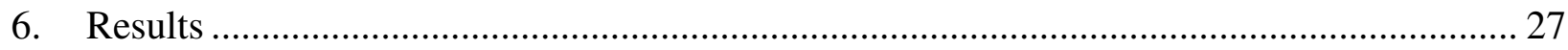

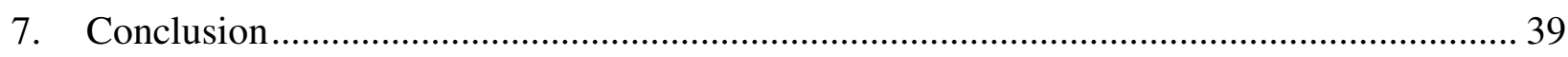

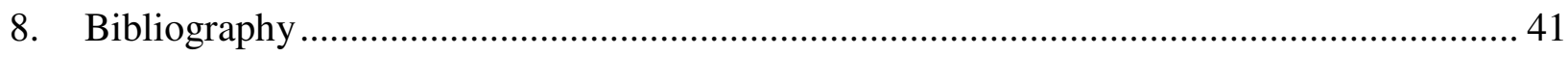

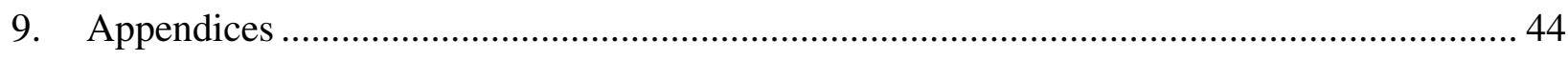

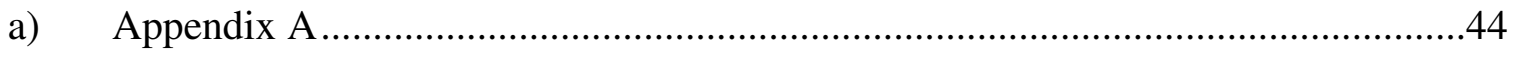

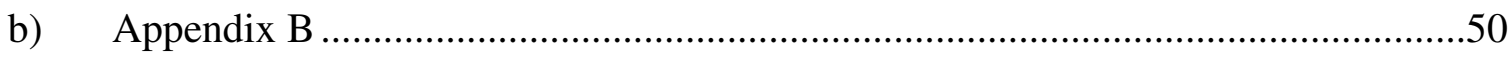




\section{List of Figures}

Figure 3.1: Revision A - Power Regulation Flow Chart................................................. 9

Figure 3.2: Main Power MOSFET Safe Operating Area (STW26NM50) [10] ............... 10

Figure 5.1: Analog Circuitry - MOSFET Driving Circuitry and Input Voltage Level

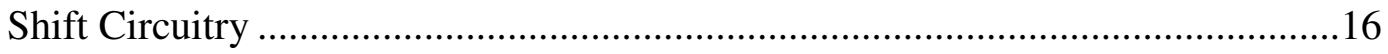

Figure 5.2: Atmel XPLAINED Development Kit board layout overview [11]............... 18

Figure 5.3: C program flow chart ……………………................................................ 20

Figure 5.4: Input voltage verification code snippet ................................................... 24

Figure 5.5: IRFP260N thermal model used to determine temperature threshold ............. 25

Figure 5.6: Heat sink temperature verification code.................................................. 26

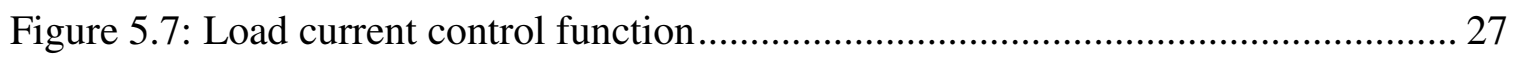

Figure 6.1: Single module, microcontroller, heat sink and dollar bill for scale .............. 28

Figure 6.2: Full testing setup with three modules without the SUT ................................. 29

Figure 6.3: Load Current vs. Varying Control Voltage - Each module tested independently and all three in parallel........................................................... 30

Figure 6.4: Load current of each individual module while collectively being used in

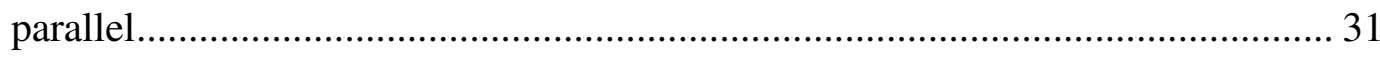

Figure 6.5: Differential Instrumentation Amplifier [13]................................................ 33

Figure 6.6: Current Sense Resistor voltage measured at the PCB and the resistor terminals while changing the current control voltage ........................................... 34

Figure 6.7: Power loss for each module when used individually ..................................... 35 
Figure 6.8: Load step change from $0 \mathrm{~A}$ to $5 \mathrm{~A}-\mathrm{Ch}$. 1: current control voltage; Ch. 2:

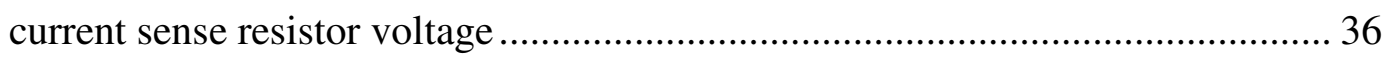

Figure 6.9: Load step change from 5A to $0 \mathrm{~A}-\mathrm{Ch}$. 1: current control voltage; Ch. 2:

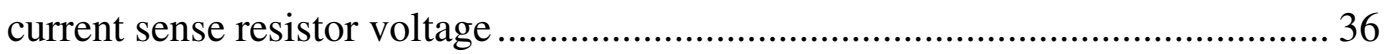

Figure 6.10: $0.5 \mathrm{~V}$ current control voltage impulse to perform a 5A impulse - duration:

10ms Ch. 1: current control voltage, Ch. 2: current sense resistor voltage 37

Figure 6.11: Linear Technology LT1351 op-amp, large-signal transient waveform from data sheet $-A_{V}=1, C_{L}=10,000 p F[14]$ 


\section{List of Tables}

Table 4-1: Digitally Controlled, Modular Electronic Load Design Specifications

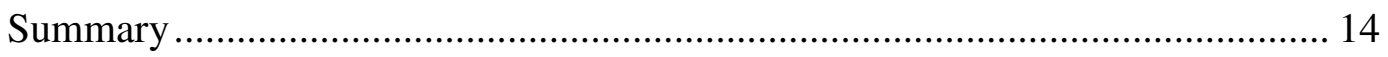

Table 5-1: ATXMEGA128A1 Feature Overview [12]................................................... 19

Table 5-2: Thermal model component descriptions ………………………………..... 25

Table 6-1: Measured Load Current vs. Current Sense Resitor Votlage vs. Current

Sense Resistor Voltage Meausred at PCB for Module 1 ................................... 32

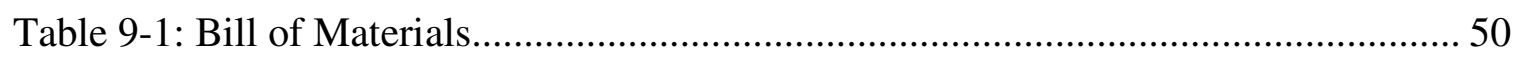




\section{INTRODUCTION}

The purpose of this project is to design and build an inexpensive, modular electronic load. This load is designed to be used by people who would like to acquire an electronic load at limited budget. Hence, the unit needs to be inexpensive. The unit is designed to also be very reliable and simple in construction so that inexperienced engineers can use it with little to no knowledge of how it works.

Now what is an electronic load? An electronic load is a device that can sink current from any other device. It is actually like a variable resistor, in other words, a potentiometer. It takes as much current from the device under test as the electronic load

module states. The unit has a range and anywhere in that range, it can draw current from the device under test.

Electronic loads are used primarily to test power supplies to verify that they are working as specified. Realistically, it can be used to test anything that needs a constant draw of current from it.

Most electronic loads, like the proposed electronic load, are designed to handle a maximum amount of current at a specified voltage. Generally they have a maximum current or a maximum power rating specification. Commercially available electronic loads can start out at hundreds of dollars and work their way up to thousands of dollars, especially as the amount of current they can sink increases.

The proposed electronic load is designed to work at a maximum amount of current with a specified voltage but with an added ability that allows it to reach higher currents in a different way. The load is designed to increase the maximum current by 
allowing more units to be placed in parallel. Thus, if more than the present maximum current is needed, it can be easily accommodated by adding another module to the main unit. In other words, the proposed electronic load offers flexibility with respect to maximum output current capability. This particular design is better than most other electronic loads because the individual module in the proposed electronic load can be built with low power parts, which are less expensive and still handle high current because of the parallel feature. That possibility alone makes it worthwhile and attractive for people such as the hobbyist and university students because if they do not need a high current electronic load, they can use a single module that will meet all their needs. 


\section{BACKGROUND}

When engineers build an electrical system they need a way to verify that the system will work under some semblance of normal working conditions [1]. For example, a power supply is built to deliver power to a load such as a laptop or desktop computer, microprocessor or application-specific integrated circuit, or even a battery [2] [3] [4]. As in many other electrical systems, a power supply needs to go through some load testing to verify its operation. This is where the electronic load plays an important role because it can mimic the load that would force current (hence, power) to be delivered from the power supply. This type of testing is critical especially to evaluate voltage regulation ability of the power supply where output voltage at no load will be compared with output voltage at full load.

A load is defined as something that draws a specified current from the electrical system. Hence, a resistor or potentiometer is commonly used as a test load to an electrical system. Sometimes during the testing of the system, resistors that can handle lots of power are often used to load the system. The use of resistors has a downside though, because they have to be able to dissipate a specific amount of power or they will burn up. Thus, careful attention should be given to measure the correct power rating of the resistor before using it as a test load.

When a power supply, as an example, is designed to output 100, 200, or even 1000 watts of power, resistors become impractical. For lower power supplies, resistors that can dissipate 10 s to 100 s of watts can be used, but they are costly and can produce lots of heat which is not ideal to have around electronics. Also, with resistors, specific 
values have to be obtained to ensure that the proper current is drawn from the power supply so that it is loaded correctly. Pulling too much current could damage components and pulling too little current will not adequately test the power supply. To vary the current, resistance would have to be adjusted as well and this could be cumbersome and impractical since many different values of resistance may be required to obtain the right combination. Since resistors come in discrete values of resistance, they would have to be arranged in parallel and series combinations to obtain the correct resistance to draw the correct amount of current. Trying to arrange resistors to get exact resistance values is difficult at best and therefore another option would be to use a continuous resistor, or a potentiometer.

Still, a potentiometer that could dissipate 10 s to 100 s of watts would need to be acquired and those are not only expensive, but also less available than low power potentiometers. Moreover, they have a resolution to maybe 100s of milliamps. A more realistic option is what is referred to as an electronic load. In essence, an electronic load acts as a variable resistor that is controlled electronically.

Electronic loads are designed to be able to sink a certain amount of current from the power supply based on input from the user. They can be adjusted from no load up to at least full load of the supply, and most electronic loads can be used for higher loads than a certain power supply under test can handle. Electronic loads can also be very precise with a resolution of 100 s of micro-amps or even better which makes them more attractive to use than resistors.

The electronic load described in this report was initially proposed by a former student of California Polytechnic State University (Cal Poly), Jonathan Paolucci, who is 
currently an engineer at Linear Technology. He came up with the basis for this design to allow for inexpensive testing of projects at Linear Technology. Here, a professional company with a big IC market wanted to save money and build their own electronic load. That reason alone makes this project very useful. For the first time, upon successful completion of the proposed electronic load, a piece of test equipment can be sold at an inexpensive price with a small footprint and can be made available for the smaller entities while minimizing the cost.

What a lot of small entities use in lieu of having an electronic load is a variable resistor box. This device is basically multiple power-sized potentiometers that are placed in series and can be adjusted down to the ohm. Each potentiometer represents a different order from one ohm up to 100k ohms and they are adjustable in discreet increments, 0-9 in that order of magnitude. These resistor boxes work great for applying any load to a power supply, but the major drawbacks are that they are big, bulky, dissipate lots of heat, and are not very accurate with small currents. For those reasons, they are inefficient when testing power supplies and was a big cause for the creation of the electronic load.

Various types of electronic loads have been created over time ranging from loads that use switching DC-DC converters and resistor combinations, to switching converters that recycle the power back to the power grid or even to batteries. One such load that has been proposed uses a buck converter where the current sink capability is controlled by the specified output resistance and the switch's duty cycle. This design is unique because it uses a proven DC-DC converter to create a load. The output resistance is chosen based on the amount of current the load needs to sink with the given output voltage of the buck converter. The current can be varied by adjusting duty cycle which in a buck converter 
varies the output voltage. With a set resistance and changing output voltage, output current is now varied. This design has a couple of disadvantages; first, the output resistance needs to be calculated and modified based on the current this load needs to sink. Another disadvantage is that the output resistance must be able to handle high power or this load will not work anyway. There is also the problem with voltage drops across multiple components and wire lengths and therefore requires an auxiliary voltage source in series with the input voltage if the input voltage is too low for the converter to function [5].

Another unique electronic load is one that feeds back to the grid power to dissipate the power absorbed by it. Because this load does not have a power dissipating device attached to it, the topology for acting as a load is vastly different. Since it is connected back to the grid, this topology must do something to control the DC current from the Source Under Test (SUT) and then it must invert it to AC to feed back to the grid. This style of electronic load is impractical when applied to the idea of inexpensive electronic loads. A major concern of all electronic loads is what to do with the power sinking into it. This load deals with it by sending the power back to the grid as opposed to just wasting it as heat. A drawback of sending the power back to the grid is that infrastructure must be installed and regulated as to the power company's specifications which in itself can be a tedious task. There is also the issue of the amount of current this load can sink. It is not an expandable device for more power, but on the other side the grid does not care how much power is being sent back to it [6].

A final design to look at is a load which is basically a compilation of the previous two loads. The design combines the use of a switching converter to transfer the SUT's 
current to the "load" and the ability to transfer the power to a rechargeable battery or back to the grid as well. This load may work great but it still has the problem of expandability and expense. The scope of this project is to design an inexpensive and expandable electronic load that can work with any power for the less critical market [7].

The previous discussions make up just a few of the designs currently used as electronic loads. So what makes the Digitally Controlled, Modular Electronic Load better? There are three answers to that: price, simplicity, and modularity. The price point of this load is around \$100. A 150W load from B\&K Precision, which would be equivalent to the power rating of one module, has an MSRP of $\$ 525.00$ [8]. Granted, the B\&K Precision load currently has more features, but not $\$ 425$ more. Most of the added features are addable to the microcontroller in this design. This proposed electronic load has a simplistic design to it as well which will be discussed more in Section 5. And finally, the one thing this design can do that none of the others are capable of is a modular structure. If more power needs to be sunk, then more modules can be placed in parallel to accomplish this task. The previous mentioned designs do not allow for a modular design and are therefore limited at a maximum power limit. 


\section{Previous Work}

This project originally started out as a culminating project for a Bachelor of Science degree, designing and building the analog version of this digital, modular electronic load. The analog version had many of the same design requirements as its digital counterpart will have. It was able to detect the input voltage and if the input voltage rose above $60 \mathrm{~V}$, the load would turn off. When the input voltage rose above $30 \mathrm{~V}$, the load would drop to half current. This meant that the maximum current sinkable with an input voltage over $30 \mathrm{~V}$ would be $5 \mathrm{~A}$ per module. The analog version also had an over temperature control so that if the heat sink temperature rose above $85^{\circ} \mathrm{C}$, the load would shut off until the temperature dropped below that threshold. The current limit was inherently built into this design, forcing it to stop at $10 \mathrm{~A}$ because the reference voltage only varied between $0-1 \mathrm{~V}$. As long as the reference voltage could not increase above $1 \mathrm{~V}$, the input current could not increase above 10A. Further background on how the analog modular electronic load operated is reported in [9].

The first two revisions of the analog modular electronic load required further improvements, but with each revision better performance was obtained. One issue experienced in the first revision was that the voltage regulators could not handle the load placed on them from the different components. It was recommended after the first design to obtain more robust voltage regulators and redesign the power regulation circuit so the regulators would stop failing. It was suspected that the daisy chain design, shown in Figure 3.1, where the $12 \mathrm{~V}$ regulator started the chain and then used subsequent voltage regulators to step down to lower voltages was the cause for malfunction. This daisy chain 
design created extra current draw on specifically the $12 \mathrm{~V}$ and $5 \mathrm{~V}$ regulators causing them to fail more frequently than any other. It was also observed that the low output current specification from the $12 \mathrm{~V}$ and $5 \mathrm{~V}$ regulators did not help the reliability of this circuit.

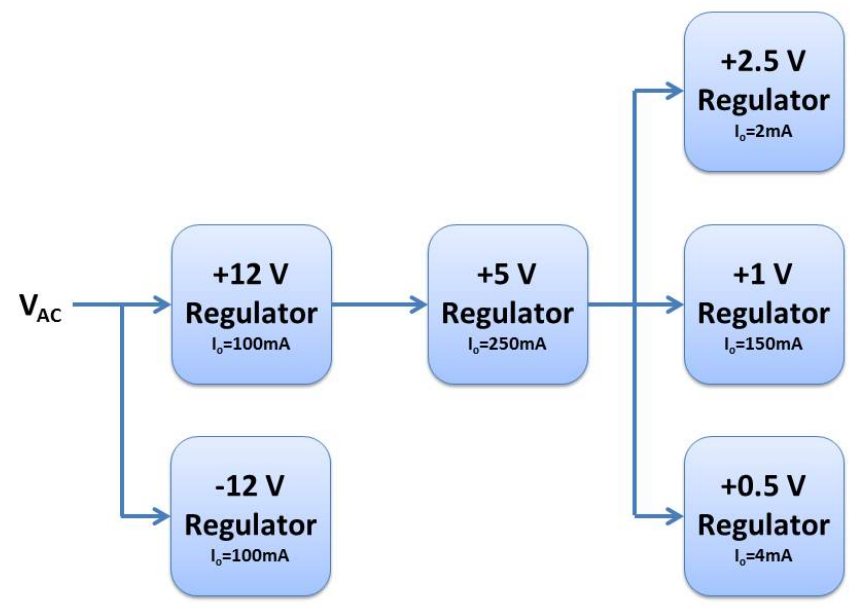

Figure 3.1: Revision A - Power Regulation Flow Chart

Another major issue with the first design was the amount of current sunk into the electronic load. The load was designed to deliver 10A but the first design could only sink 5.44A. It was speculated that the cause for this was the insufficient power regulation circuitry and that making the load more robust would keep the reference voltage regulators from loading. This in turn would make the voltage regulators capable of handling more current draw and therefore remain in constant voltage mode as opposed to constant current mode. With that thought in mind, nothing was done to the main circuitry to increase the amount of current being sunk or rather, to make it so that the correct amount of current was sinkable.

In the second revision, it was noticed that the load could sink 7.65A per module which was an improvement and attributable to the modification of the power regulation circuit but still not enough to allow this design to go to market. Further investigation was required to determine the cause for this drastic current difference. Upon further 
investigation of the power MOSFET in the datasheet, it was discovered that the one specification trying to be competent and aware of, was actually the specification that was causing the design to not reach its full potential.

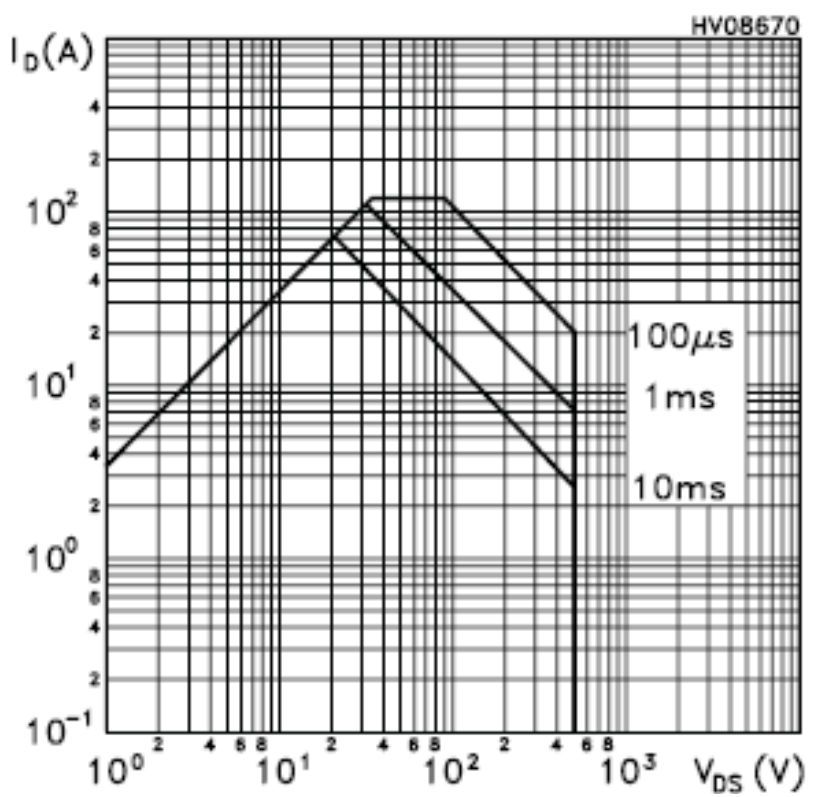

Figure 3.2: Main Power MOSFET Safe Operating Area (STW26NM50) [10]

Figure 3.2 shows the Safe Operating Area (SOA) of the MOSFET. The original requirement pertaining to the $\mathrm{SOA}$ was that $\mathrm{V}_{\mathrm{DS}}$ could reach $60 \mathrm{~V}$ and still maintain $10 \mathrm{~A}$. It was quickly realized that that requirement would be unobtainable and therefore was relaxed to $5 \mathrm{~A}$ when $\mathrm{V}_{\mathrm{DS}}$ rose above $30 \mathrm{~V}$. It was also required that a $\mathrm{V}_{\mathrm{DS}}$ under $30 \mathrm{~V}$ would still allow the current to reach 10A. Upon further examination of the SOA, it was realized that a $\mathrm{V}_{\mathrm{DS}}$ below about 3 or $4 \mathrm{~V}$, the drain current would start to decrease at a rate of about $3 \mathrm{~A} / \mathrm{Volt}$. It was also realized that the input voltage was $3.3 \mathrm{~V}$ giving a VDS of $0.85 \mathrm{~V}$. The SOA would then predict that the drain current for that VDS would be about 5A. Assuming that the SOA chart is more of an approximation instead of exact data and that the actual component does not meet specifications exactly, a measured drain current of 7.65A would not be unreasonable data. Given these new insights and knowledge of an 
SOA, it was determined that a new MOSFET needed to be found with a significantly lower $\mathrm{R}_{\mathrm{DS}-\mathrm{ON}}$ resistance. The STW26NM50 MOSFET had an $\mathrm{R}_{\mathrm{DS}-\mathrm{ON}}$ of $100 \mathrm{~m} \Omega$ and therefore a new MOSFET needed to be found with less on resistance. 


\section{Design REQUIREMENTS}

The digitally controlled, modular electronic load is a unique electronic load because it theoretically does not have a maximum current specification. Because this design is modular, the more current needed to be sunk means more modules need to be placed in parallel. Even though the overall design can theoretically allow for infinite current, each module cannot and therefore has a maximum current specification.

Each module is designed to handle $5 \mathrm{~A}$ at $30 \mathrm{~V}$ or a maximum of $150 \mathrm{~W}$. The voltage limit for the load is placed at $60 \mathrm{~V}$. Since each module can handle a maximum of $5 \mathrm{~A}$, multiple modules can be placed in parallel to obtain higher currents. For example, if two modules are placed in parallel, then the full load would be 10A; three modules would be $15 \mathrm{~A}$ and so on. The scope of this project will limit the maximum current to $15 \mathrm{~A}$ or three modules. To do this, each module will exhibit current sharing so that the current being sunk will be evenly split among the number of modules present.

This thesis will also aim to improve the previous implementation by converting the analog circuitry to digital circuitry. An inexpensive microcontroller will be used to control the load's operation as opposed to the analog comparators. To simplify costs, the design will be expandable so that only one microcontroller is needed for a specific number of modules.

As previously implied, a major design requirement of this project is that it has a small, inexpensive footprint. Since there is a possibility the modules would have to be installed and uninstalled often, they would need to be small and light weight for people to manage them. The electronic load should also be efficient enough that an enormous heat 
sink will not be needed to facilitate power dissipation. The footprint for a module would be somewhere around twenty-five square inches. Anything smaller and the heat would not be able to escape the module and anything much bigger would not be attractive for practical implementation.

The proposed electronic load would also be inexpensive so that schools, small businesses, and hobbyists would be able to purchase the electronic load and as many modules as they need for their application without the high cost. If this electronic load were to be put into mass production, ideally it would be sold for somewhere less than \$100. As a comparison, the electronic load currently used in the Power Electronics Lab at California Polytechnic State University is typically sold for around $\$ 500$.

Since the proposed electronic load could be used by designers with a lack of experience in power supply design and loading, multiple protections will be put into place so as not to damage the load during testing. This design will have overvoltage, over-current, and over-temperature protection circuitry to keep any parts from breaking by inexperienced users. Of course, none of the protection circuitry in this electronic load will protect the source under test. That is the responsibility of the operator to know how to hook this load up and the limits of the source being tested.

This project will also incorporate a current meter to verify the amount of current sinking into this load. There is no voltage meter on this unit because the wires connected from the power supply to the load have a small amount of resistance and a high current load could add a voltage drop making the voltage reading errant. A separate voltmeter would make for a better voltage measurement because minimal current would flow on those leads. 
Table 4-1 has a summary of the design specifications for this project.

Table 4-1: Digitally Controlled, Modular Electronic Load Design Specifications Summary

\begin{tabular}{|cc|}
\hline \multicolumn{2}{|c|}{ Summary of Design Specification per Module } \\
\hline Maximum Input Current / module & $5 \mathrm{~A}$ \\
\hline Maximum Input Voltage & $60 \mathrm{~V}$ \\
\hline Maximum Power & $150 \mathrm{~W}$ \\
\hline Protection & $\begin{array}{c}\text { Over-Voltage } \\
\text { Over-Temperature } \\
\text { Over-Current }\end{array}$ \\
\hline Control Circuitry & Micro-Controller \\
\hline Size/module & $\sim 25$ inches \\
\hline Cost & $<\$ 100$ \\
\hline
\end{tabular}




\section{DESIGN}

The main idea behind the proposed electronic load is that it be simple and cost efficient. This overarching goal drives the design of the load and the concept of modularity which is the most prominent feature of this design.

The proposed load is designed to have over-voltage protection, over-temperature protection, over-current protection, and over-power protection with a small footprint. These requirements are met by using the concept of modularity. By making each module handle less current, all components and wiring sizes can be reduced for a lower current/power level. Then adding more modules in parallel allows the total current this load can sink to increase. Since this load is digitally controlled, it has two parts to each module; the digital section and the analog section.

\section{a) Analog Circuitry}

The analog portion of this design consists solely of the driving circuitry for the MOSFET that sinks the current and a voltage divider that shifts the input voltage to the appropriate range. The schematics for these two circuits are shown in Figure 5.1. The MOSFET driving circuit functions by a reference voltage coming in on CRNT to the non-inverting terminal of the operational amplifier (op-amp). The CRNT reference voltage comes from a digital to analog converter on the microcontroller and will be discussed in more detail in the next section. The op-amp compares the CRNT voltage with the voltage from the current sense resistor to control how hard to turn on the MOSFET. If CRNT increases, the op-amp will see that CRNT is greater than the current 
sense voltage and increase the gate voltage of the MOSFET to turn it on harder, allowing more current to flow, thus increase the current sense voltage until is matches CRNT.
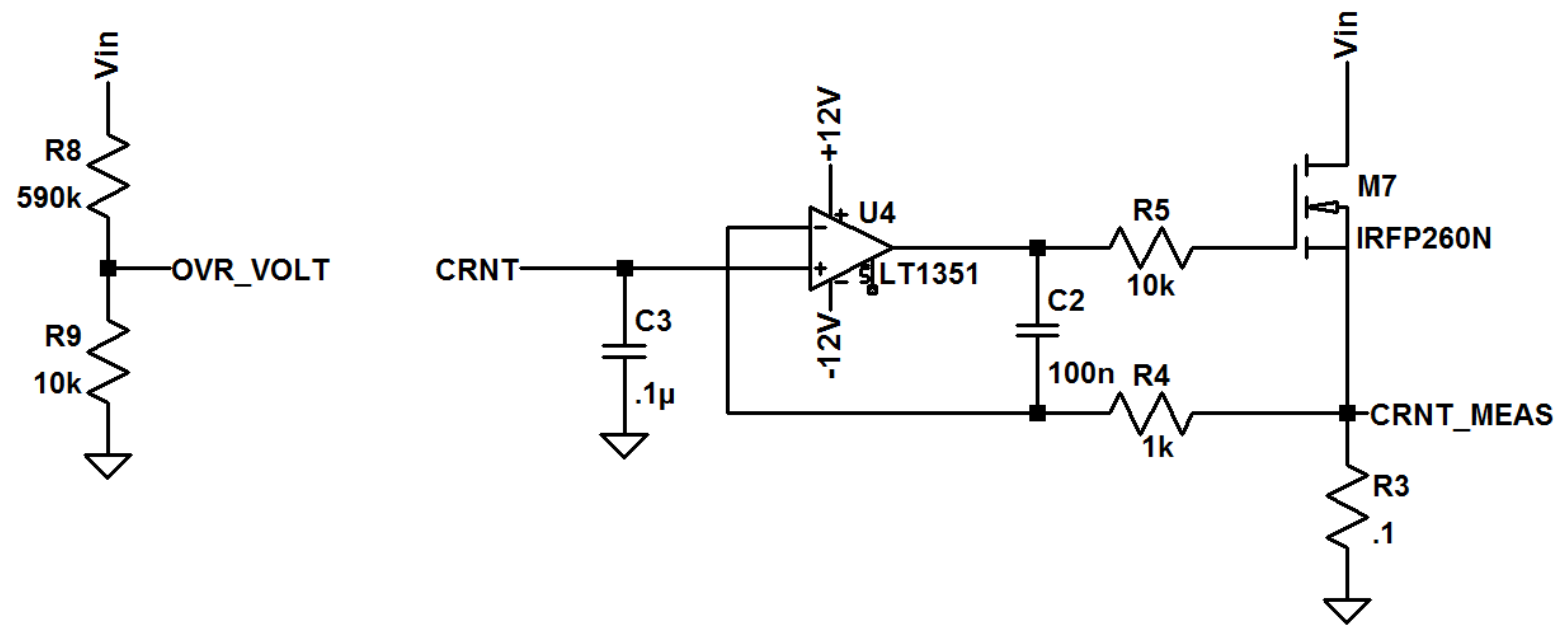

Figure 5.1: Analog Circuitry - MOSFET Driving Circuitry and Input Voltage Level Shift Circuitry

The output of the op-amp drives the gate of the MOSFET, M7. M7 is an International Rectifier, IRFP260N, MOSFET with a $\mathrm{V}_{\mathrm{DS}}$ of $200 \mathrm{~V}$, an $\mathrm{R}_{\mathrm{DS}-\mathrm{ON}}$ of $0.04 \Omega$, and an $\mathrm{I}_{\mathrm{D}}$ of 50A. As mentioned in Section 3, the previous MOSFET was inadequate for this design and a new MOSFET needed to be chosen. The main requirement driving the change was to obtain a lower $\mathrm{R}_{\mathrm{DS}-\mathrm{ON}}$ resistance. An equally driving requirement was that it be able to dissipate $300 \mathrm{~W}$ to provide power dissipation headroom and if desired, allow each module to dissipate more than $150 \mathrm{~W}$ of power. The last driving requirement for this choice was that the SOA needed to be such that the $\mathrm{R}_{\mathrm{DS}-\mathrm{ON}}$ would not interfere with operation limiting the maximum current at lower voltages and that the MOSFET was capable of $5 \mathrm{~A}$ from $0 \mathrm{~V}$ to $60 \mathrm{~V}$.

MOSFET, M7 is connected to $\mathrm{V}_{\mathrm{IN}}$ and the current sense resistor, R3, to ground. The source under test (SUT) sinks its current in M7 while R3 is used to control the amount of current through M7. The voltage across R3 is fed back to the inverting input of 
the op-amp and used as described above to control the current in the load. R3 was chosen to be $0.1 \Omega$ because the lower the resistance, the less power is dissipated through it due to Equation 5-1.

$$
P=I^{2} R=5^{2} * 0.1=2.5 W
$$

If the resistance was increased, the power dissipation would be increased and therefore the heat produced by the power being dissipated. The other reason to choose this size resistance was because the voltage drop across this resistor due to the current thru it, would be at a feasible level. If the resistance increased to say $1 \Omega$, the voltage drop across it would be $5 \mathrm{~V}$ which would still be adequate for the op-amp to function, but now there will be an order of magnitude increase in the power dissipation. If the resistance is lowered, the voltage drop across it would become unusable due to noise, if lowered enough, and make it difficult to get a reference voltage that could match it with any resolution. If, for instance, the resistance dropped to $0.01 \Omega$, the power would decrease by an order of magnitude which would be beneficial, but so would the required reference voltage. Instead of needing a reference voltage that peaked at $0.5 \mathrm{~V}$, it would need one that peaked at $50 \mathrm{mV}$.

Components, R4, R5, and C2 are used as part of the control loop to help stabilize the op-amp and keep it from oscillating. C3 is used as a low-pass filter to stabilize the input to the op-amp and filter out any AC noise that might exist on that bus.

The input voltage level shifter drops the range of the input voltage of $0 \mathrm{~V}$ to $60 \mathrm{~V}$ down to $0 \mathrm{~V}$ to $1 \mathrm{~V}$ to be in range for the analog to digital converter that will detect when the input voltage rises above $60 \mathrm{~V}$. More will be discussed on the operation of the analog to digital converter in the next section. 


\section{b) Microcontroller}

The digital circuitry portion of this project for simplicity was contained on a development board. The development board used was an Atmel XPLAINED Development Kit that contained an Atmel ATXMEGA128A1, 16 bit microcontroller. An overview of the development board layout can be seen in Figure 5.2.

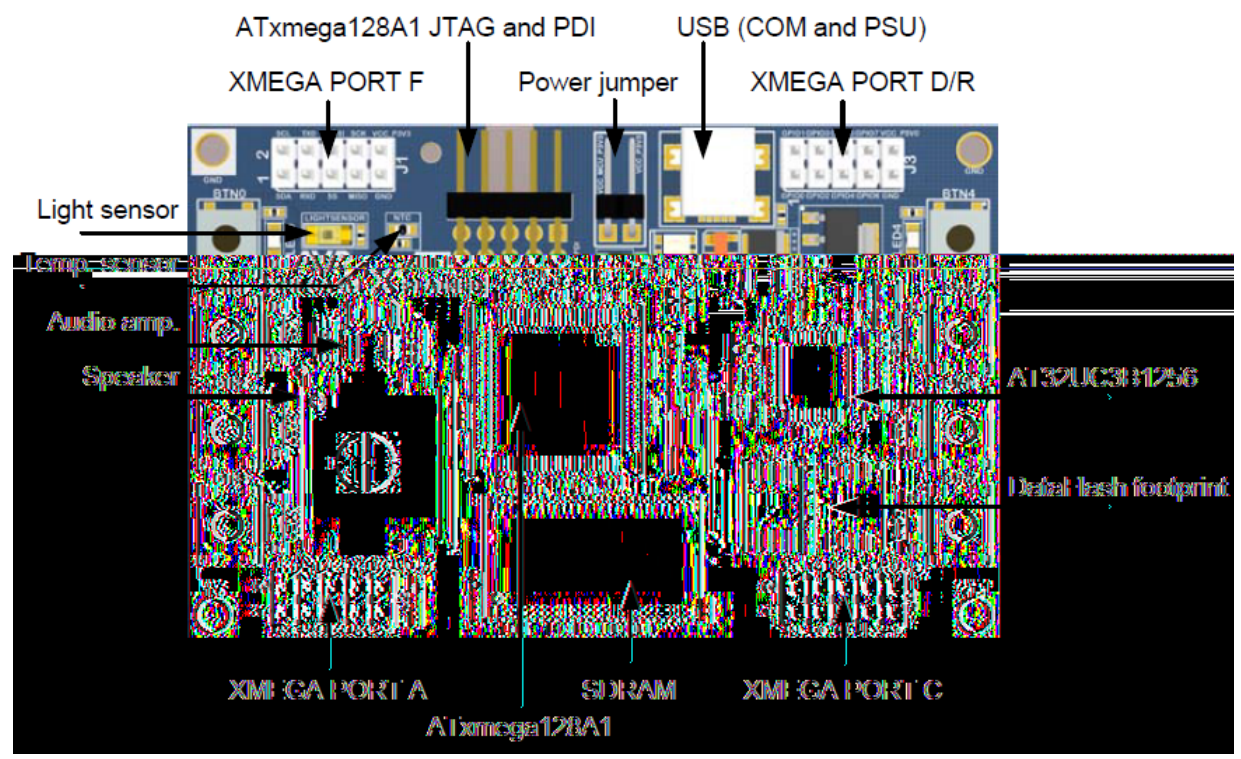

Figure 5.2: Atmel XPLAINED Development Kit board layout overview [11]

Why was Atmel ATXMEGA128A1 (XMEGA) chosen as the microcontroller for this design? The "digital" portion of this design was fairly sophisticated and needed a microcontroller that could handle everything. There are multiple types of microcontrollers on the market such as PICs, Arduinos, or smaller Atmel chips. This design required $\mathrm{ADCs}$ to measure the input voltage, current of each module, and heat sink temperature of each module. The other microcontrollers could have been chosen instead of the XMEGA, but to make the digital design more simplistic, the XMEGA was chosen so that additional features would not have to be designed. The focus of this project was on the load portion, not the digital design and therefore, design time was kept 
to a minimum for the digital portion. An overview of the features present on the XMEGA can be seen in Table 5-1.

Table 5-1: ATXMEGA128A1 Feature Overview [12]

\begin{tabular}{ll}
\hline Parameter & Value \\
\hline Flash & $128 \mathrm{Kbytes}$ \\
Max. Operating Frequency & $32 \mathrm{MHz}$ \\
CPU & 8 -bit AVR \\
Max I/O Pin & 78 \\
SPI & 12 \\
ADC Channels / Resolution / Speed & 16 / 12 bits / 2000 ksps \\
DAC Channels / Resolution & 4 / 12 bits \\
Analog Comparators & 4 \\
Operating Voltage & 1.6 to $3.0 \mathrm{~V}$ \\
\hline
\end{tabular}

In the previous version of the load, before a microcontroller was added, analog comparators and reference voltages were used to control the load and all the safety functions. With the introduction of the microcontroller, those features of the load were moved to the microcontroller.

\section{Program Flow}

To control the electronic load, a $\mathrm{C}$ program had to be written and programmed to the microcontroller. This program required certain values to be captured through the $\mathrm{ADC}$ and verified to set values before continuing. For instance, the input voltage needed to be verified that it was not greater than $60 \mathrm{~V}$ before allowing the current to be increased. The program flow is shown in Figure 5.3. 


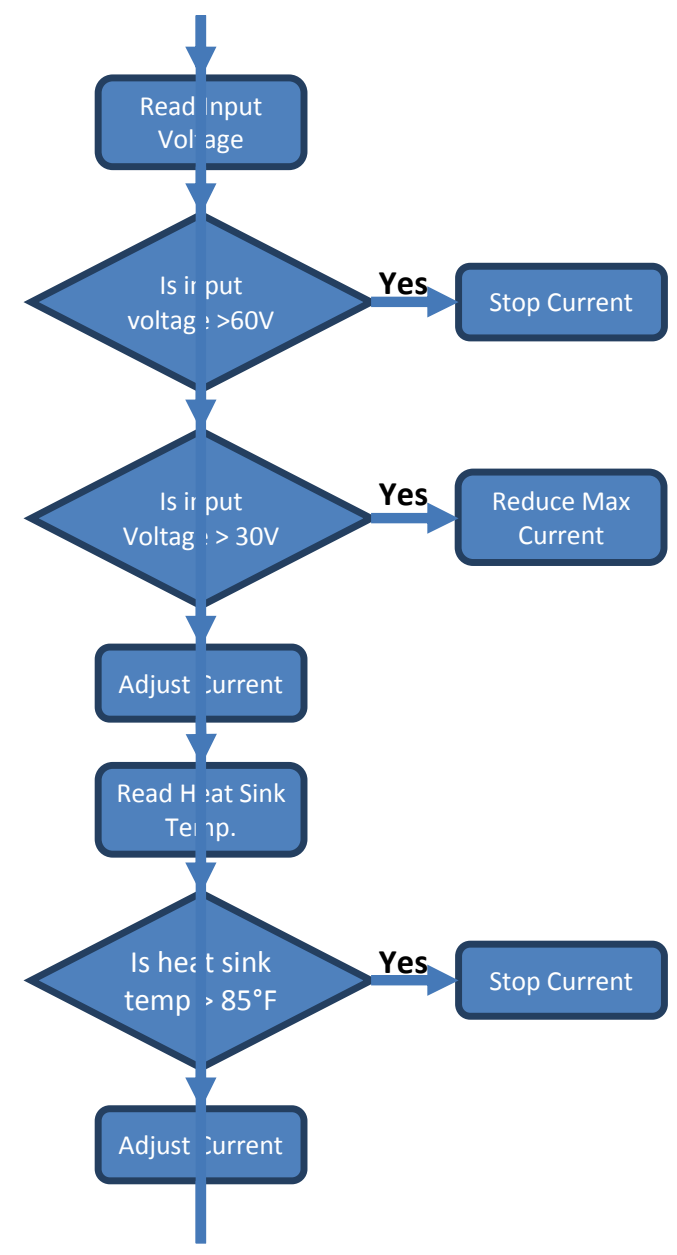

Figure 5.3: C program flow chart

After the microcontroller is initialized, this portion of the program begins and continues on an endless loop as long as the load is powered on. Each one of these sections will be discussed below.

\section{Microcontroller Initialization}

The microcontroller has ADCs, DACs, switches, and LEDs to initialize and each component must be setup correctly for it to work when called later in the program. The full initialization procedure can be seen in the complete code set in Appendix A. 
When starting the initialization process, certain header files must be included.

Each of the following header files provide easy access to the microcontroller registers to assist in the initialization of each device. These header files were all created by Atmel for the XMEGA microcontroller with the exception of stdio.h and stdlib.h which are standard C libraries.

$$
\begin{aligned}
& \text { Included header files: } \\
& \text { - avr_compiler.h } \\
& \text { - board.h } \\
& \text { - adc_driver.c } \\
& \text { - adc_driver.h } \\
& \text { - avr/io.h } \\
& \text { - avr/interrupt.h } \\
& \text { - stdio.h } \\
& \text { - stdlib.h }
\end{aligned}
$$

With the header files added, the microcontroller must program each register to set up each peripheral. The first to be set are the LEDs. The General Purpose Input / Output (GPIO) pins are set as output while the switches are set as input. Both the LEDs and switches are active low devices. In the case of a switch, when the switch is pressed, that switch represents one bit in a byte. When that switch is pressed, that bit pulls low changing the bit value from one to zero. All other bits in that byte remain high unless multiple switches are pressed. Because the switches are active low devices, they have pull-up resistors that must be engaged as well so that when the switch is not engaged there is an open circuit condition which puts $\mathrm{V}_{\mathrm{CC}}$ on the GPIO pin for that switch to give a logic high condition.

There are four channels that can be used for digital to analog conversion but only one of them is used in this design. In future designs, the other three DACs could be used 
one per module or one per two modules but some analysis would need to be done first. For this design one DAC output will be used to control all three modules.

Since only one DAC will be used, it is the only one that will be initialized and is called DACA.CH0. The DAC will be initialized with a 1V reference in single channel conversion mode. By using a $1 \mathrm{~V}$ reference, the maximum output voltage of the DAC will only be $1 \mathrm{~V}$. With a 12 bit DAC and a \pm 2 LSB of accuracy, a 1 bit change will correlate to a $0.244 \mathrm{mV}$ change $\pm 0.488 \mathrm{mV}$ based on (5-2) where $\mathrm{N}$ is the number of bits.

$$
V_{D A C}=\frac{N}{0 x F F F} * V_{R E F}
$$

After enabling the DAC, a calibration offset was set so that the output of the DAC at $0 \mathrm{x} 000$ would actually be $0 \mathrm{~V}$. Originally, when the DAC output 0x000, the output voltage was $7 \mathrm{mV}$. With a calibration offset of $0 \mathrm{x} 016$ the offset error present in the DAC will be compensated.

The ADCs were setup similarly but the calibration for the ADCs was given in a driver file included with the headers. The calibration for the ADC was such that predetermined values from Atmel were loaded to the ADC calibration register. The ADCs function differently from the DACs because the twelve ADCs can only store their values in four result registers and the more ADCs used result in longer delays between each measurement because only one ADC can capture a measurement at a time, store it in a result register and transfer it out before the next measurement can be obtained. Currently, only three ADCs are being used, an increase that would be made in future revisions, therefore each $\mathrm{ADC}$ input has an independent result register. Because the three ADCs need measurements taken and they cannot be taken at the same time, the ADC must be initialized to sweep through these three specific ADCs without wasting time 
capturing data from the unused ADC channels. Therefore, the ADC is setup to sweep through channels five, six, and seven while storing the data from each ADC channel in result register zero, one, and two which is also swept through.

The sixteen ADC channels are broken into two groups of eight channels and for this design, each group is configured so all eight channels use an unsigned conversion mode, with 12 bit resolution, a reference voltage of $1 \mathrm{~V}$, and clock prescaler of eight meaning that the ADC clock takes the system clock and divides it by eight defining the sample rate and conversion rate of the ADC. Again the reference voltage of $1 \mathrm{~V}$ means that the maximum voltage the ADC can assign a digital value to is $1 \mathrm{~V}$. Anything over that voltage will saturate the ADC and it will just give the maximum hexadecimal value to the limit of $\mathrm{V}_{\mathrm{CC}}+0.5 \mathrm{~V}$.

Each ADC channel was initialized identically and therefore will not be discussed individually. Each channel was set for single ended mode with unity gain. In single ended mode, all channels can be used in both signed and unsigned mode. Since negative values do not need to be considered, unsigned mode was used and the negative input to the ADC was connected to half the reference voltage minus a fixed offset voltage.

The final step in the initialization process is to enable the ADC to wait a set amount of time for it to be ready. The following sections describe the operation of the load as described in the Program Flow section.

\section{Input Voltage Verification}

The first part of the program flow is to check the input voltage. Just as was done in the analog version, if the input voltage rises above $60 \mathrm{~V}$, all current must be stopped so 
that the MOSFET maximum power rating of $300 \mathrm{~W}$ is not exceeded. The portion of code used to check the input voltage can be seen below in Figure 5.4.

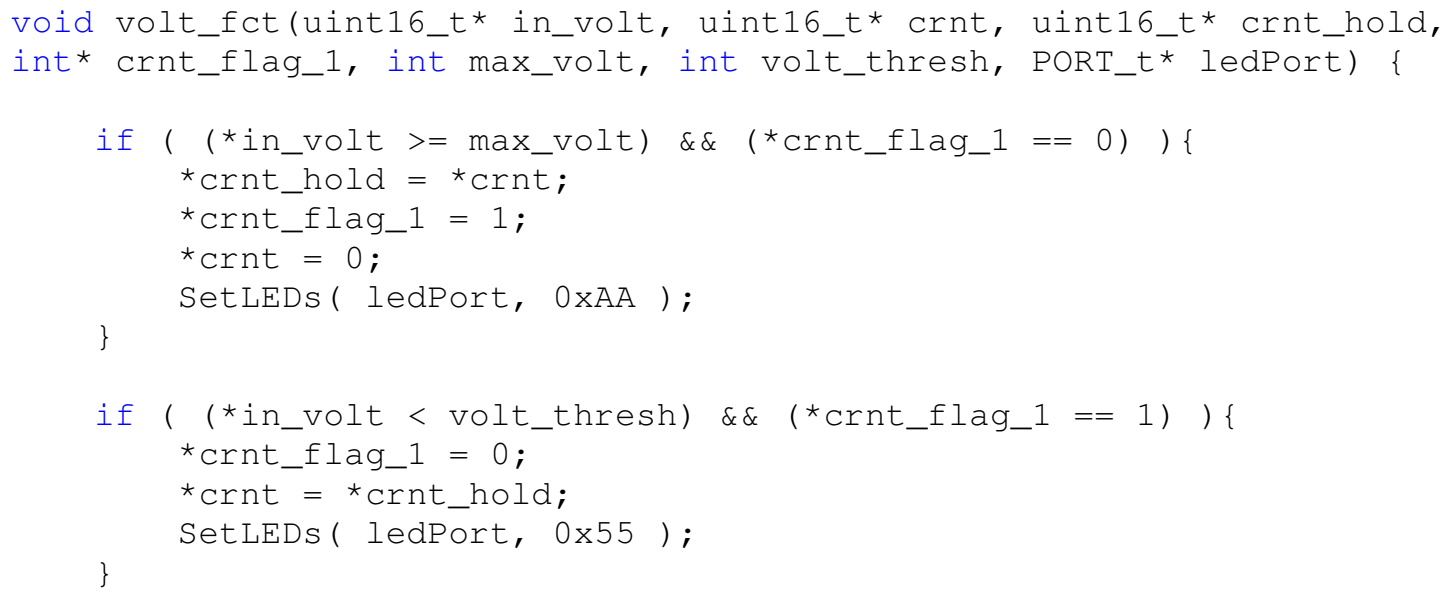

Figure 5.4: Input voltage verification code snippet

One of the benefits noticed in using this format for checking the input voltage and then setting the maximum current variable to dictate what the maximum voltage the DAC can output to control current flow means that this load can be configurable for multiple MOSFETs and power ratings. One could program this code so that at $25 \%$ of the maximum input voltage, the maximum current value could change allowing one to control the maximum amount of power the MOSFET must handle. Currently, because the MOSFET being used can handle $300 \mathrm{~W}$ of power, the maximum current value is preset to allow at most $5 \mathrm{~A}$ and to not change unless the input voltage rises above $60 \mathrm{~V}$.

If the load was built to handle $10 \mathrm{~A}$ per module, then the maximum current value could be preset to allow $10 \mathrm{~A}$ to sink. Since input voltage over $30 \mathrm{~V}$ would produce a power greater than $300 \mathrm{~W}$, the maximum current could be dropped to $5 \mathrm{~A}$ or $50 \%$ of maximum when the input voltage reaches $30 \mathrm{~V}$ to prevent dissipating too much power in the MOSFET. 


\section{Heat Sink Temperature Verification}

The purpose of this section of the program is to control the current flow compared to temperature. All MOSFETs have a maximum junction temperature rating and they will generally break if that temperature is greater than the rating. A thermal resistance model was built for this system to determine what a safe case temperature would be to not destroy the junction and was determined that a case temperature of $90^{\circ} \mathrm{C}$ would allow the junction to rise but not to detrimental levels. The thermal model is shown below in Figure 5.5. Table 5-2 is a description of the components used in the thermal model and their units of measurement.

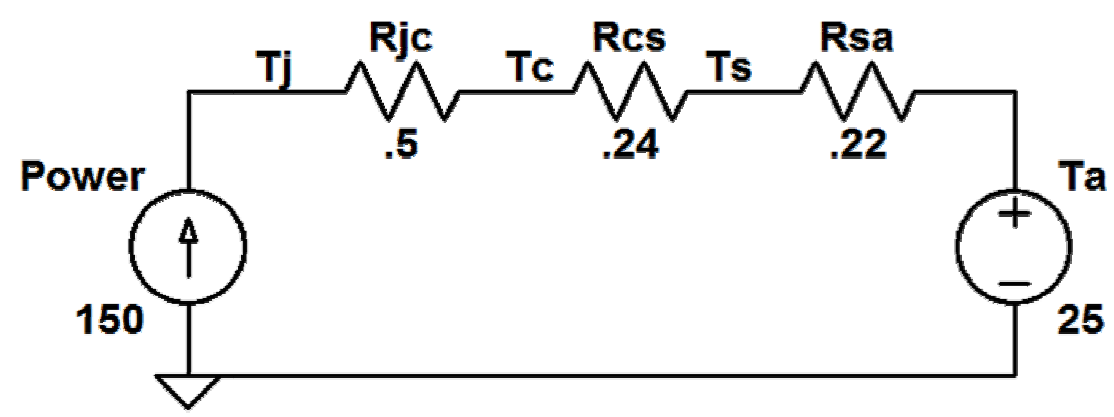

Figure 5.5: IRFP260N thermal model used to determine temperature threshold

Table 5-2: Thermal model component descriptions

\begin{tabular}{ll}
\hline Component & Description \\
\hline Power & Power dissipated in MOSFET $(\mathrm{W})$ \\
Rjc & Junction to case thermal resistance $\left({ }^{\circ} \mathrm{C} / \mathrm{W}\right)$ \\
Rcs & Case to heat sink thermal resistance $\left({ }^{\circ} \mathrm{C} / \mathrm{W}\right)$ \\
$\mathbf{R s a}$ & Heat sink to ambient thermal resistance $\left({ }^{\circ} \mathrm{C} / \mathrm{W}\right)$ \\
$\mathbf{T a}$ & Ambient temperature $\left({ }^{\circ} \mathrm{C}\right)$ \\
$\mathbf{T j}$ & Junction temperature $\left({ }^{\circ} \mathrm{C}\right)$ \\
$\mathbf{T c}$ & Case temperature $\left({ }^{\circ} \mathrm{C}\right)$ \\
$\mathbf{T s}$ & Heat sink temperature $\left({ }^{\circ} \mathrm{C}\right)$ \\
\hline
\end{tabular}

With this power level and ambient temperature, it is determined that the junction will rise to $169^{\circ} \mathrm{C}$ based on Equation 5-3 and 5-4. 


$$
\begin{aligned}
& T_{J}=\operatorname{Power}\left(R_{J C}+R_{C S}+R_{S A}\right)+T_{A} \\
& T_{J}=150(0.5+0.24+0.22)+25=169^{\circ} \mathrm{C}
\end{aligned}
$$

The maximum junction temperature is $175^{\circ} \mathrm{C}$, giving a $6^{\circ} \mathrm{C}$ cushion into this design. A larger safety factor is needed to ensure a failure will not occur and thus the need for a temperature sensor to stop current at $90^{\circ} \mathrm{C}$ is required.

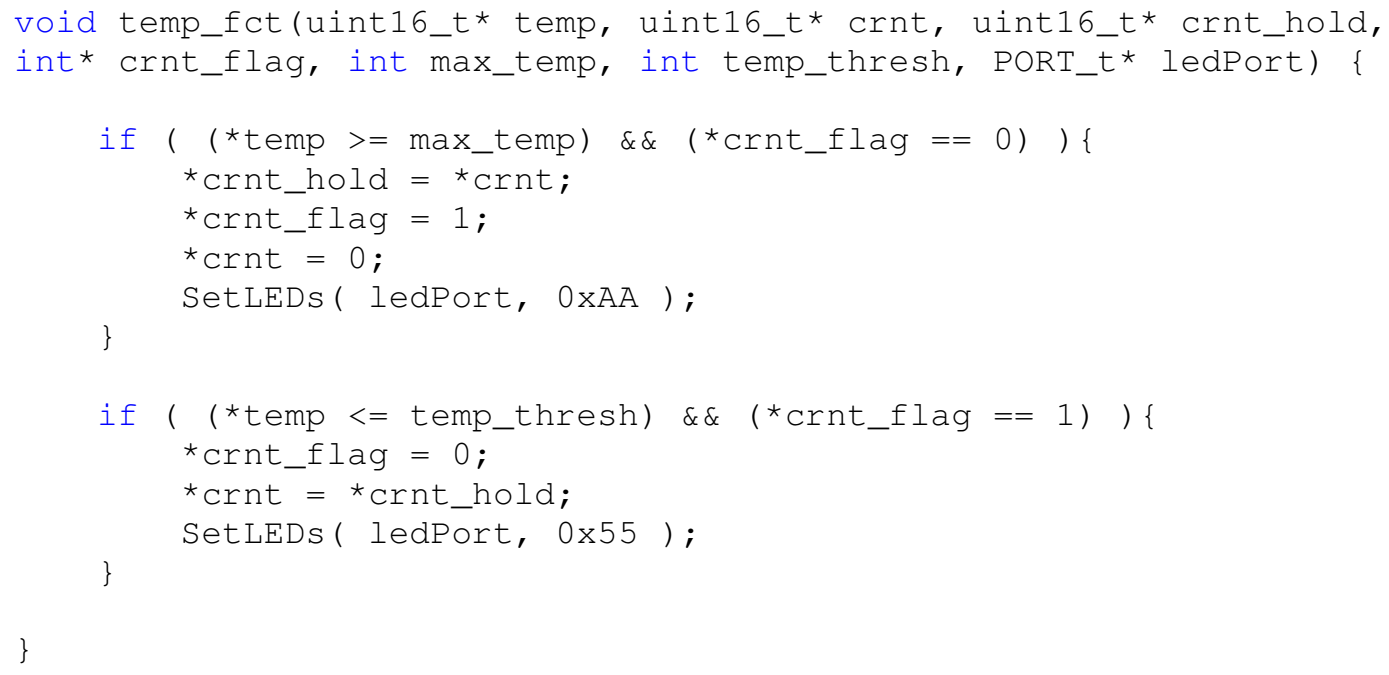

Figure 5.6: Heat sink temperature verification code

The temperature dependent, current control algorithm used to control the current of the load, shown in Figure 5.6, first obtains the present temperature of the heat sink with every cycle through the ADCs. The hexadecimal representation of that temperature is sent to a function that will be called "temp_fct". That function then checks if the sampled temperature is greater than a maximum temperature value which has been designated to be $0 x F F A$ or $90^{\circ} \mathrm{C}$. When greater than that value, some flags are set to help control the program flow and prevent other parts of the program from changing the current while shutting off current flow, thus preventing the MOSFET from overheating. When the temperature drops below $0 \times 7 \mathrm{D} 0$ or $55^{\circ} \mathrm{C}$, indicating that the heat is dissipating from the load, the load current will be allowed to flow again and the other portions of the 
program will take back over controlling the current in the load until the temperature rises to that level again.

\section{Load Current Adjustment Function}

The load current adjustment function is the main control unit for the load. Without this function, no current would flow through the load. This function, shown below in Figure 5.7, is used primarily to increase and decrease the amount of current to sink in the load. In the initialization stage, the DAC that controls the amount of current is set to 0x000 therefore starting all current at 0A. As discussed earlier, other functions control the maximum current and whether the current flow needs to stop. This function is used to control the amount of current. Two buttons, buttons four and five, are used to increment and decrement respectively. They work by clicking them; they can perform their function and increment milliamps at a time. They also work by holding them down and will vary on the order of about 5-12mA while incrementing a counter that when the threshold is reached, starts varying at the rate of $50-75 \mathrm{~mA}$. It is designed so that one can get from $0 \mathrm{~A}$ to $5 \mathrm{~A}$ very quickly if necessary while also allowing for fine adjustments. Buttons zero, one, and two are used for step changes. One can press those and step from 0A to 5A or 5A to $0 \mathrm{~A}$ with one press of a button. These buttons would not be used in a formal release but are used for quick testing purposes. 


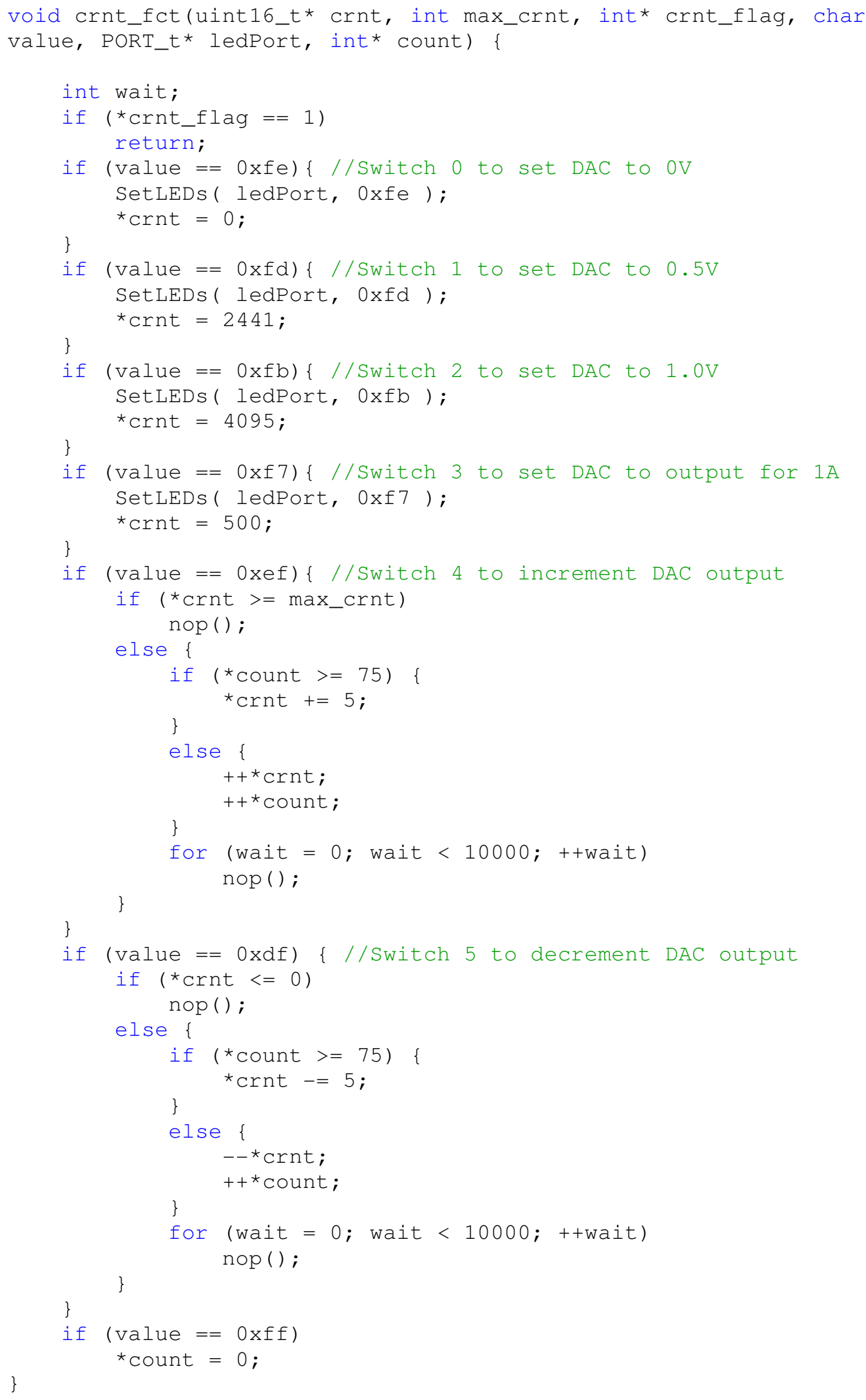

Figure 5.7: Load current control function 


\section{RESUlts}

The verification of this design was done in two stages. The first stage was to verify that the $\mathrm{C}$ program written and programmed to the microcontroller functioned correctly and in the appropriate manner. The microcontroller was then connected to the modules to verify they operated correctly before finally connecting them in parallel to verify operation. This is shown in Figure 6.1.

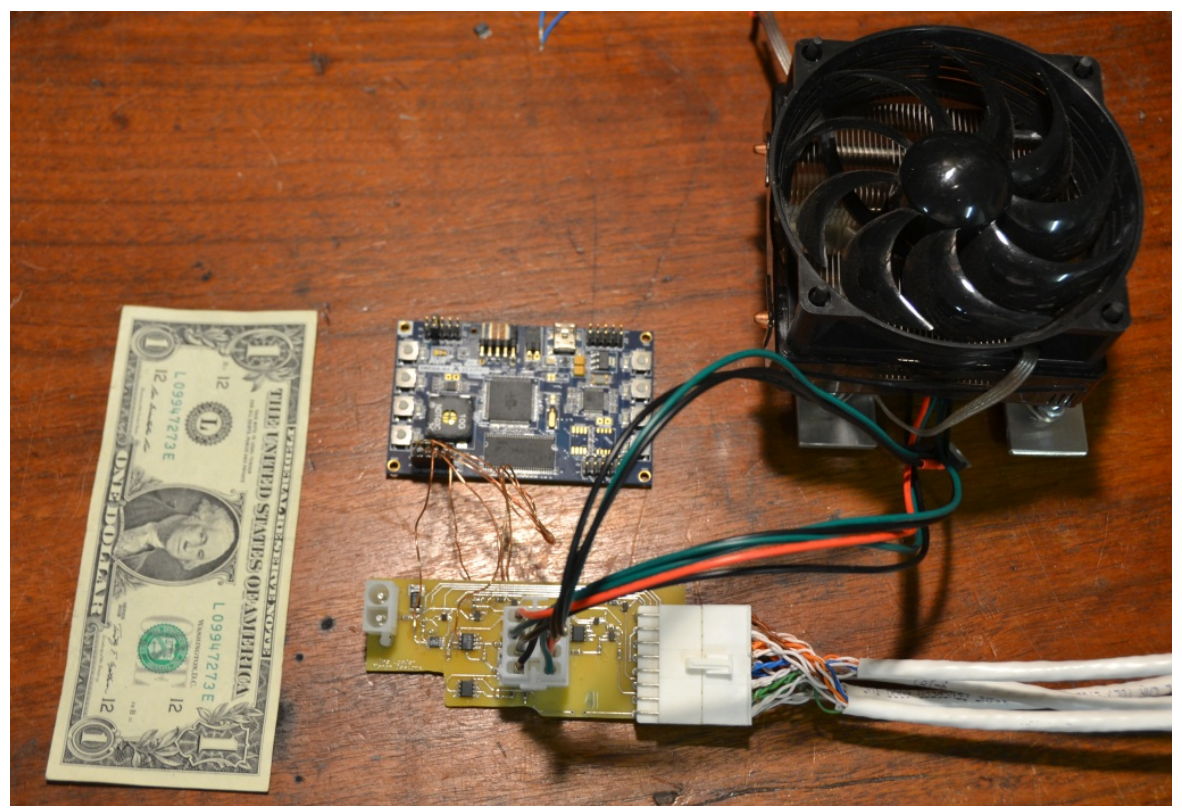

Figure 6.1: Single module, microcontroller, heat sink and dollar bill for scale

Verifying operation of the microcontroller was straightforward but involved many iterations of the program to obtain the correct threshold and maximum hexadecimal values for the DAC and ADC. Once a general program flow was created, the microcontroller was tested independently by connecting it to multimeters and voltage sources. The voltage sources were modified so as to trip a safety feature or verify that 
certain parts of the program worked and verification was done by either seeing a change on the DAC or using the LEDs available on the development board as debugging devices.

Once the program's main features were debugged, connection to one module was performed to verify operation. This involved using a high current power supply as the Source Under Test (SUT) connected to the module and using the microcontroller to control the load module as depicted in Figure 6.2. This task was performed on all three modules individually before connecting them in parallel and performing the same testing. Figure 6.3 shows the data obtained in those tests which display some rather interesting observations.

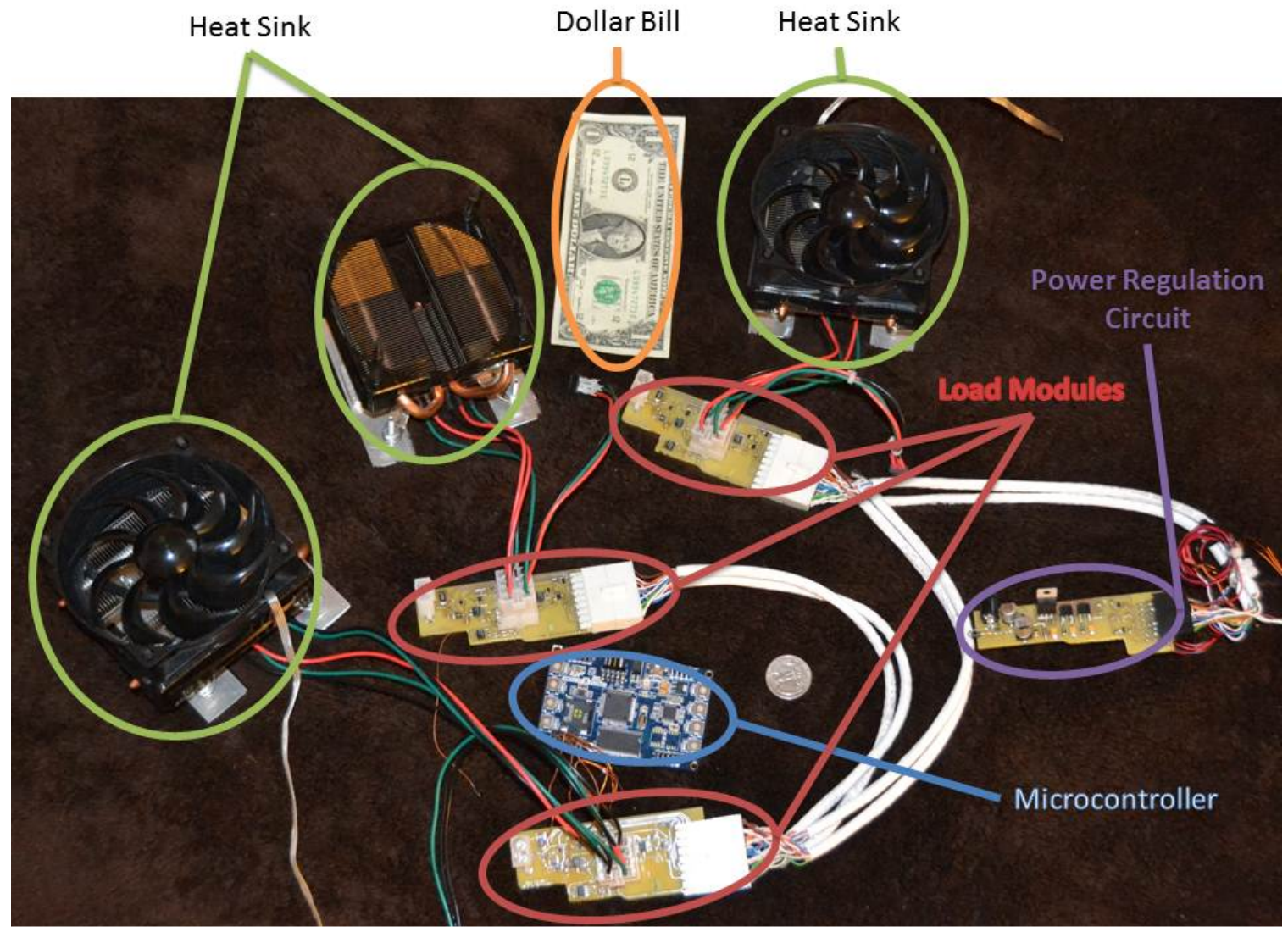

Figure 6.2: Full testing setup with three modules without the SUT 
The first observation is that Module 3 has that current jump at higher current control voltages. This outlier is unexplainable except for the fact that Module 3 had the worst performance in all testing and therefore may have had a damaged or out of tolerance component that only showed issue at high current. As evident in the rest of the graph, Module 3 follows the trend and closely resembles the other modules and therefore, the high current issue could also be explained by different parasitics present or more apparent at higher currents.

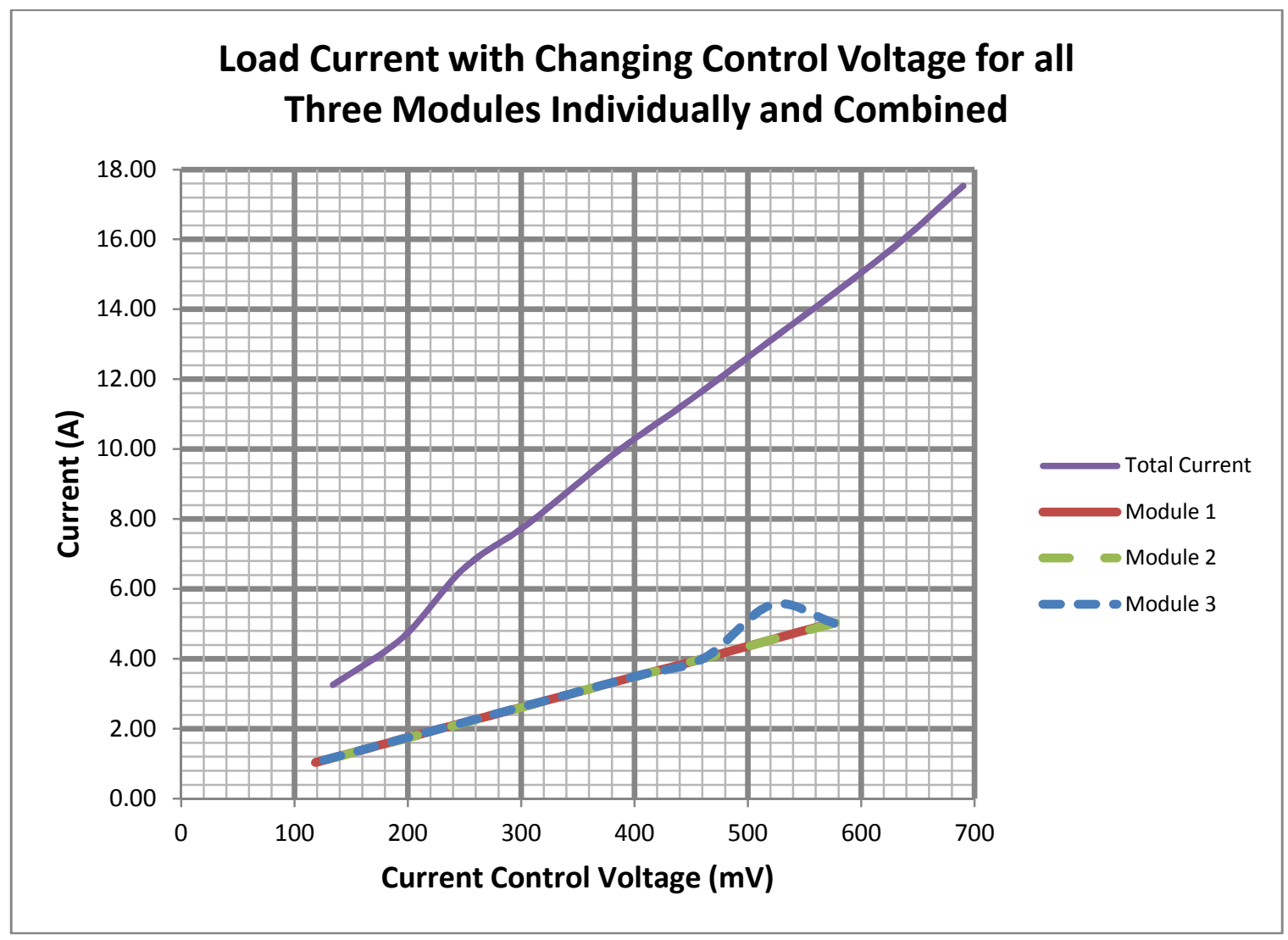

Figure 6.3: Load Current vs. Varying Control Voltage -

Each module tested independently and all three in parallel.

One of the major issues seen in testing the modules in parallel, or separate for that matter, was which MOSFET to use. Each module had to have a MOSFET and they were detachable from the module board since they could not be installed directly to the module 
board. This was because the surrounding components could not tolerate the amount of heat they would dissipate. Each MOSFET, current sense resistor, and temperature sensor were clamped to a computer processor heat sink to dissipate the heat generated from the current flow and attached to the printed circuit board (PCB) by 16 AWG wire. Figure 6.4 shows another representation of the "Total Current" series plotted in Figure 6.3. The three module's currents were measured independently and added together to get the total current sourced by the SUT. Figure 6.4 shows how each module varies throughout the range of load current with wide variations at higher current. This is attributable to the varying lengths of wire connecting the MOSFET and current sense resistor to the PCB and how much voltage drop each wire had at high current. The longer wires would have greater voltage drops putting a smaller voltage drop on the current sense resistor than the others and therefore when the same DAC voltage was used for each module, the current varies for each module because of wire length. A future necessity to keep the load balanced on each module would be to ensure that all wires are the same length so that the voltage drops are similar ensuring a more identical current would be present in each module. 


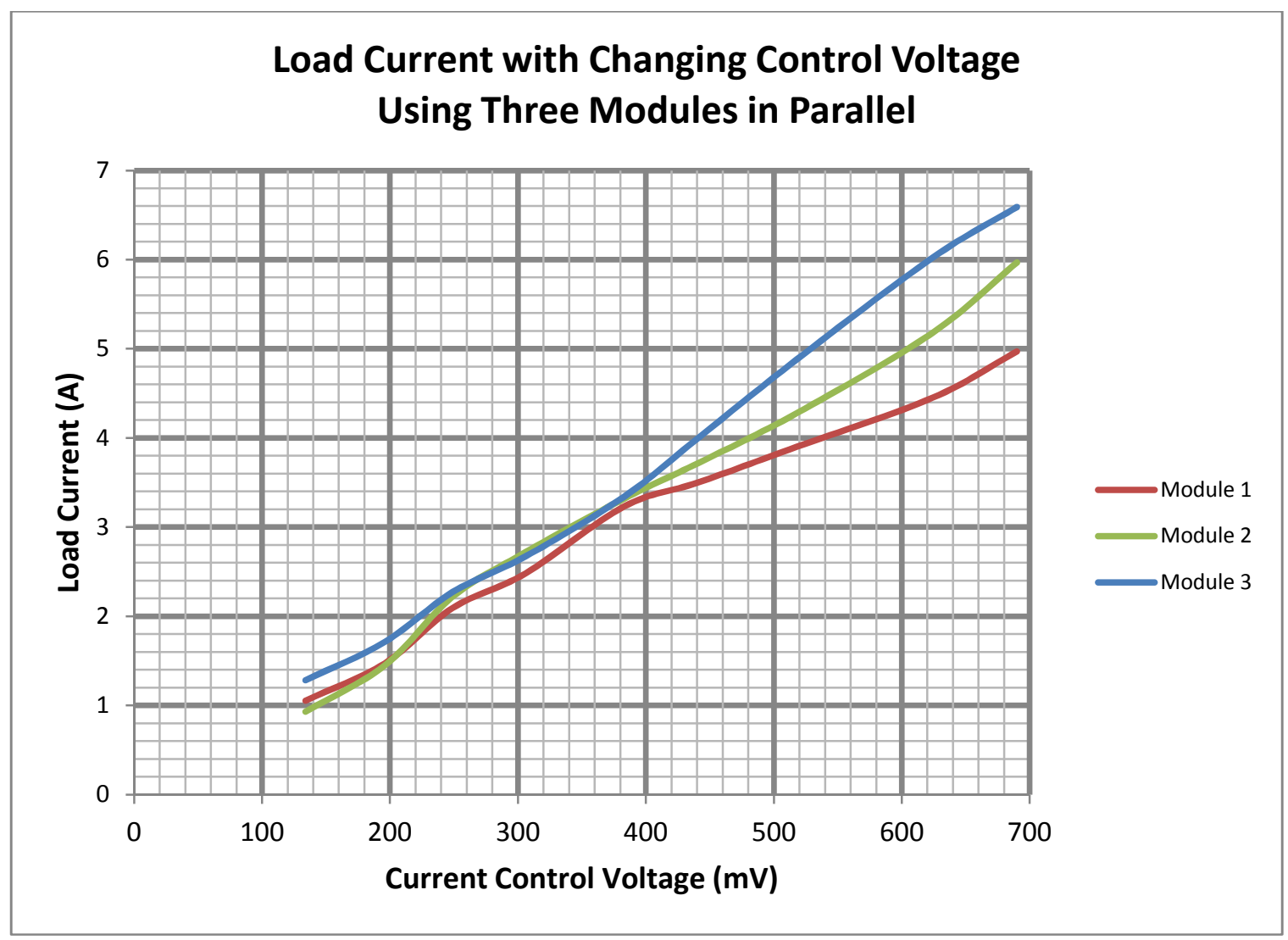

Figure 6.4: Load current of each individual module while collectively being used in parallel

The wire used to connect the MOSFET and current sense resistor to the PCB added extra voltage drops that were not accounted for originally. The higher the current, the more wire resistance is taking effect. As evident in Table 6-1, as the current increased, so did the voltage drop on the cable connecting both the MOSFET and the current sense resistor requiring the DAC to output higher voltage to try to obtain the expected current. 
Table 6-1: Measured Load Current vs. Current Sense Resitor Votlage vs. Current Sense Resistor Voltage Meausred at PCB for Module 1

\begin{tabular}{|c|c|c|c|}
\cline { 2 - 4 } \multicolumn{1}{c|}{} & \multicolumn{2}{c|}{ Current Sense Resistor Voltage Meausred at PCB for Module 1 } \\
\hline $\begin{array}{c}\text { Measured } \\
\text { Current (A) }\end{array}$ & $\begin{array}{c}\text { Measure at Resistor } \\
\text { Terminals }(\mathbf{m V})\end{array}$ & $\begin{array}{c}\text { Measured at PCB } \\
(\mathbf{m V})\end{array}$ & $\begin{array}{c}\text { Voltage Difference between } \\
\text { Resistor Measurements }(\mathbf{m V})\end{array}$ \\
\hline 5.017 & 501.01 & 542.10 & 41.09 \\
\hline 4.511 & 450.77 & 488.89 & 38.12 \\
\hline 3.981 & 398.00 & 431.43 & 33.43 \\
\hline 3.520 & 351.71 & 380.28 & 28.57 \\
\hline 3.015 & 301.60 & 326.76 & 25.16 \\
\hline 2.504 & 250.46 & 270.20 & 19.74 \\
\hline 2.061 & 206.25 & 223.20 & 16.95 \\
\hline 1.523 & 152.40 & 164.07 & 11.67 \\
\hline 1.037 & 103.88 & 112.08 & 8.20 \\
\hline
\end{tabular}

The promising statement from Table 6-1, about this design, is that the voltage measured at the resistor terminals matches fairly closely to the current measured at the SUT's terminals keeping Ohm's Law valid. A redesign would need to determine a method for measuring the voltage across that resistor at its terminals without allowing current to flow through this measurement device so voltage drop does not need to be taken into effect. Essentially a high impedance measurement device, such as a differential instrumentation amplifier, needs to be used like one shown in Figure 6.5. By using an instrumentation amplifier such as this one with input impedance of $10,000 \mathrm{M} \Omega$, a negligible amount of current would flow into it and therefore allowing it to measure strictly the voltage across the resistor and not parasitic voltages from the cable. A device like this could potentially allow the DAC voltage to be adjusted to operate over a wider range and not be limited to the $0 \mathrm{~V}$ to $1 \mathrm{~V}$ range as well. This added flexibility in the feedback circuit could also be a hazard compromising the feedback loop stability and would need to be investigated further. 


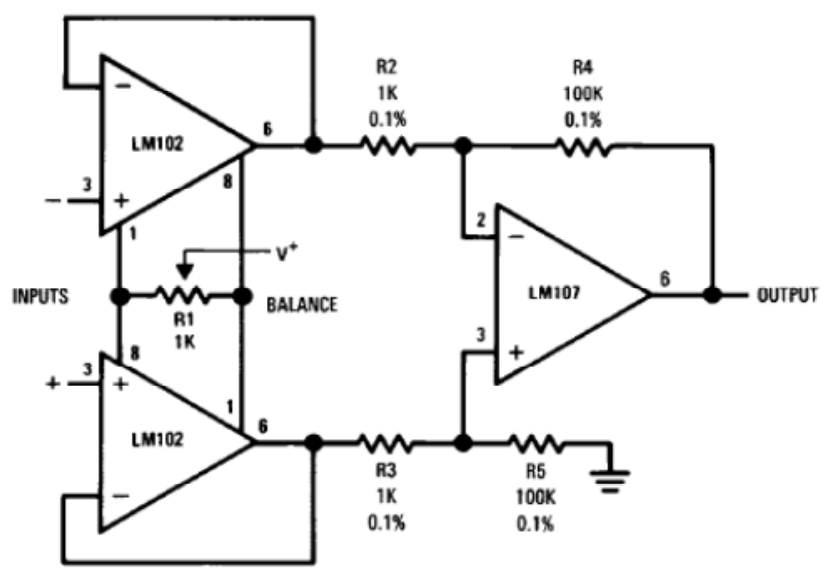

Figure 6.5: Differential Instrumentation Amplifier [13]

The main goal behind the proposed load is to output a voltage from the DAC and make that voltage be the same across the current sense resistor which dictates the amount of current flowing through the load. If the voltage across the current sense resistor could be measured accurately, then the DAC output voltage would mimic the load current almost exactly making $0.5 \mathrm{~V}$ on the DAC equal to $5 \mathrm{~A}$. As seen in testing, this was not the case. Figure 6.6 shows how much difference there was between the DAC output voltage, the current sense resistor when measure at the PCB and the current sense resistor when measured at the resistor terminals. This again reiterates the fact that a better design would incorporate a high impedance measurement device that would be used as the feedback from the current sense resistor back to the inverting terminal of op-amp U4. 


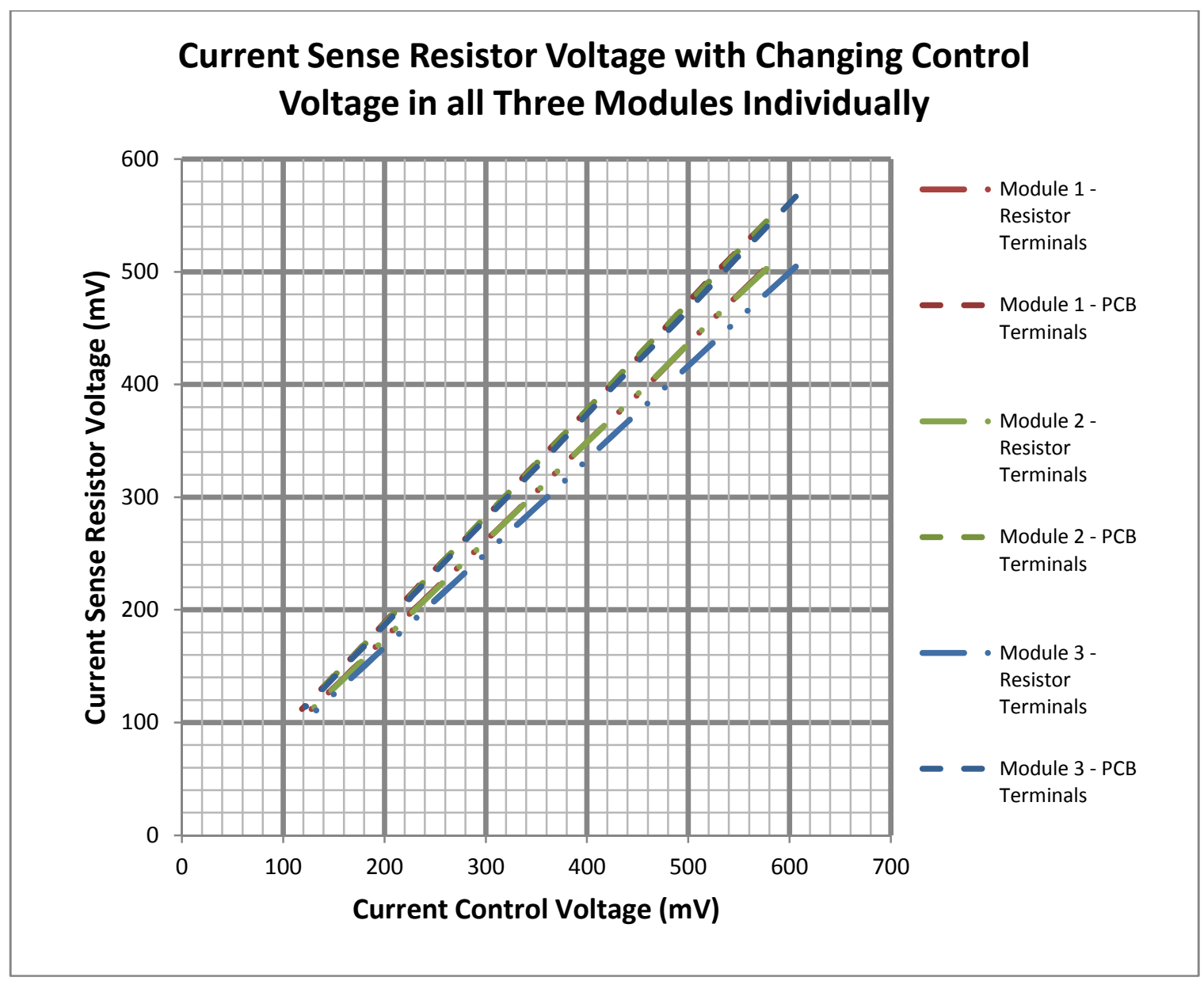

Figure 6.6: Current Sense Resistor voltage measured at the PCB and the resistor terminals while changing the current control voltage

In an effort to determine how much power was actually lost in the cable drops from the SUT to the load, the PCB to the MOSFET and the PCB to the current sense resistor, Figure 6.7 shows the power loss associated with those main issues and any other parasitics not mentioned. Since power loss is measured as input power minus output power, input power was measured by the SUT's output voltage and the current through the load. The output power is the power dissipated by the MOSFET and therefore the drain to source voltage multiplied by the load current. As expected, a rise in current would also raise the power loss. A power loss of $10.7 \mathrm{~W}$ per module at full load is a lot of 
power being dissipated in parasitic components and wires. A redesign would definitely need to take into account these losses and make a goal to minimize them.

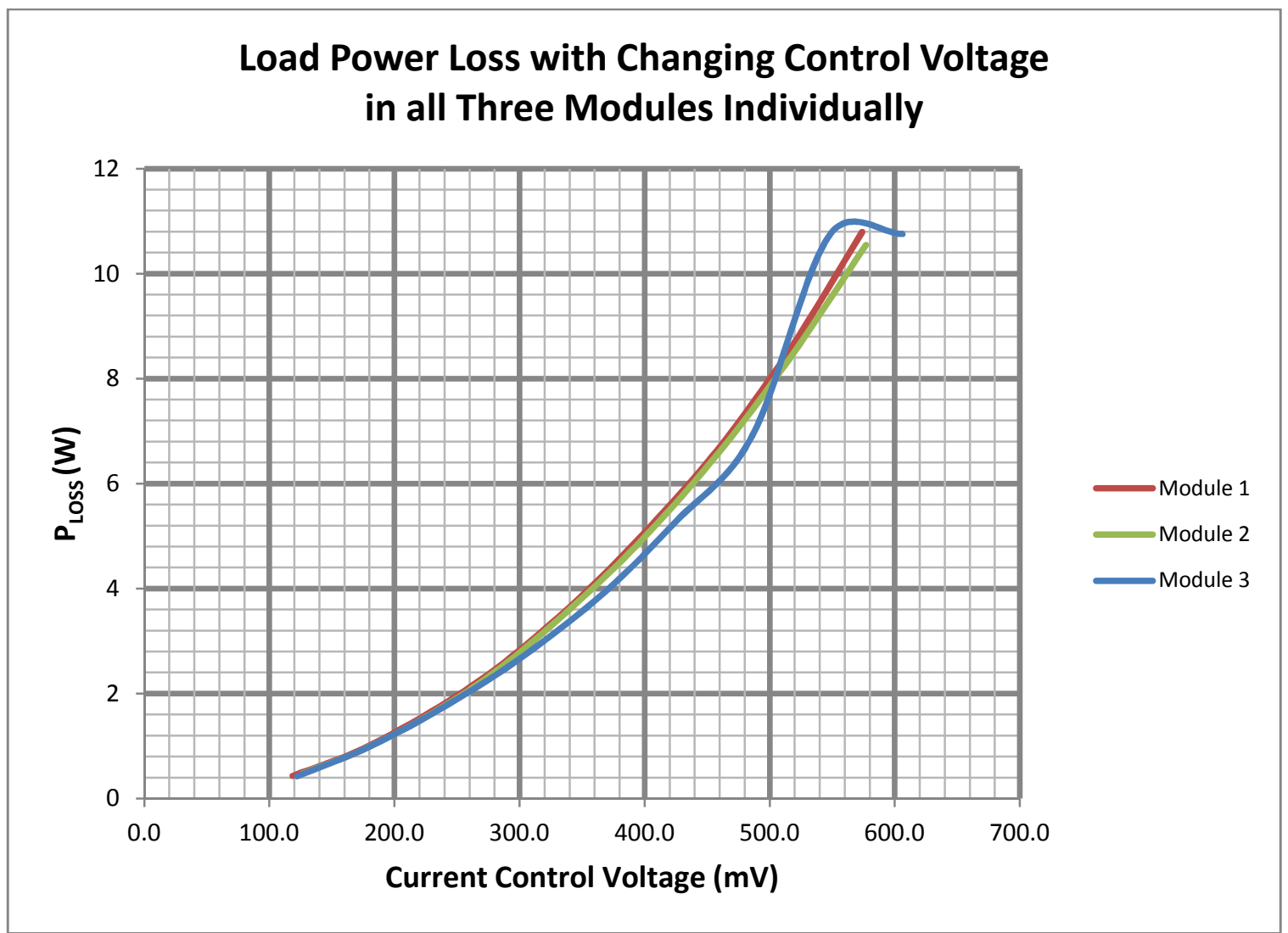

Figure 6.7: Power loss for each module when used individually

Another way to characterize an electronic load is by its settling time. Settling time is used to determine how long it takes for a step change in a device to transition to within $5 \%$ or some error window of the change that was made. For the proposed load, the settling time is characterized as the transition time from the start of the step change to when the load current is within $5 \%$ of the final value. Figure 6.8 shows the load settling time when the SUT is hit with a step load change from 0A to 5A. The settling time is approximately 0.5 seconds. Figure 6.9 shows the reverse settling time when the load starts at $5 \mathrm{~A}$ and steps down to $0 \mathrm{~A}$. The settling time increases by $50 \%$ making it nearly 0.75 seconds from the step change. 


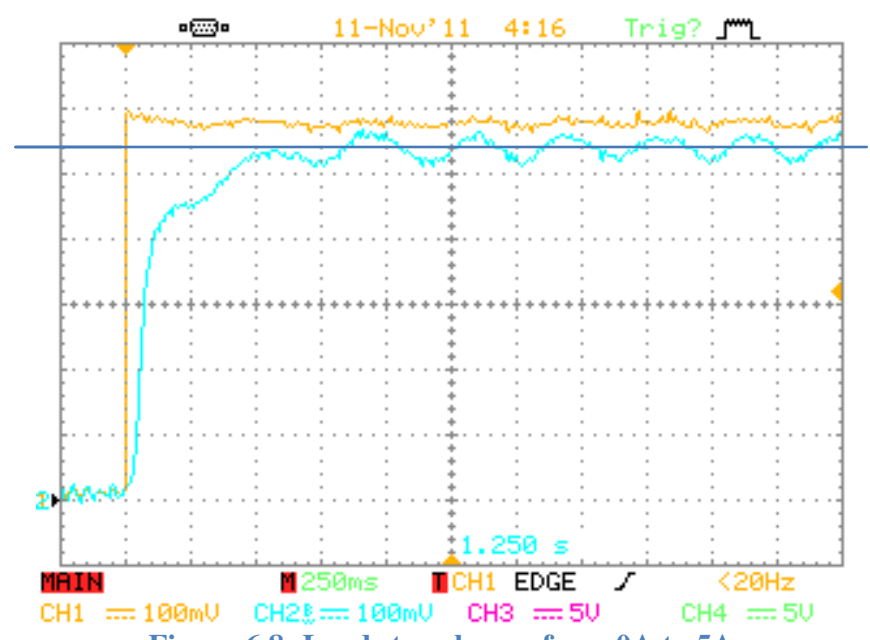

Figure 6.8: Load step change from $0 \mathrm{~A}$ to $5 \mathrm{~A}-$

Ch. 1: current control voltage; Ch. 2: current sense resistor voltage

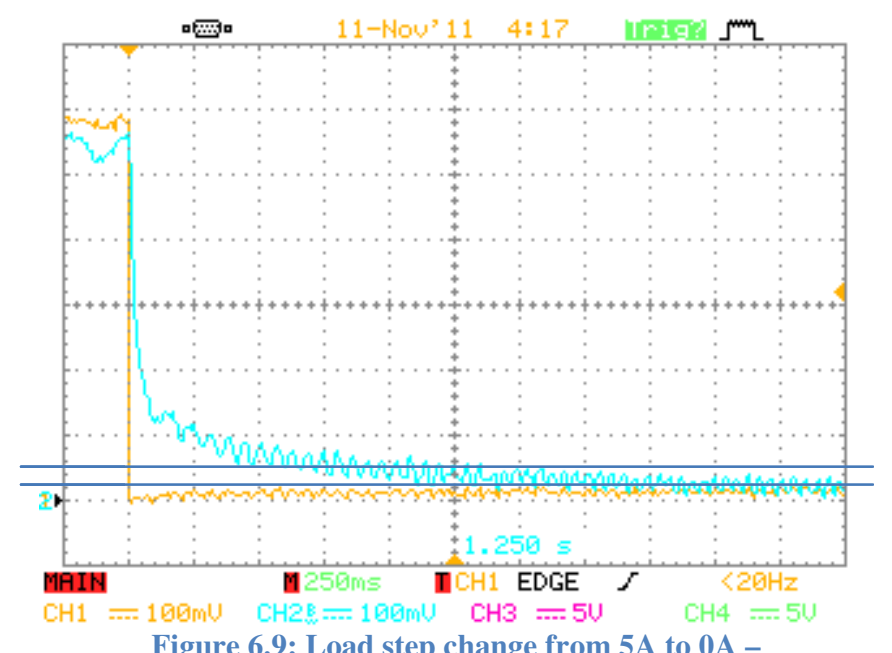

Ch. 1: current control voltage; Ch. 2: current sense resistor voltage

There is not a specific requirement or goal to be achieved pertaining to settling time but there is an interest in knowing this information. This result becomes important to users because they may be trying to apply full load on a SUT and the source has a problem with pulling 5A and the users need to quickly shut off the load, it will not immediately stop but rather continue to sink current for three quarters of a second after current flow is "stopped". This time delay could damage other parts of the circuit that otherwise may have been fine. 
A benefit of the proposed load being on a microcontroller is that it has the ability to be reprogrammed to perform new tasks and functions. One added function allowed the load to hit a source with a $10 \mathrm{~ms}$ pulse as shown in Figure 6.10. Again, it can be seen how an engineer may only want a short pulse of current to hit the load to determine the load transient response or characterize the SUT in another way and therefore only want a short duration of load current but yet even a $10 \mathrm{~ms}$ pulse has the current on for nearly one second.

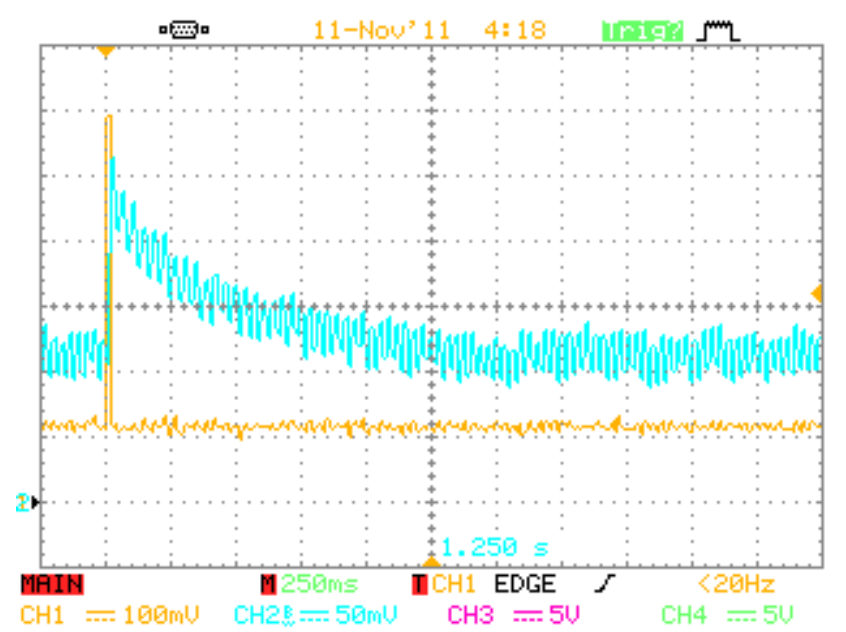

Figure 6.10: $0.5 \mathrm{~V}$ current control voltage impulse to perform a $5 \mathrm{~A}$ impulse - duration: $10 \mathrm{~ms}$ Ch. 1: current control voltage, $\mathrm{Ch} .2$ : current sense resistor voltage

A faster load would be more desirable especially for determining load transient responses of a fast SUT. The microcontroller has a $32 \mathrm{MHz}$ clock and the DAC is capable of converting 1 million samples per second. Therefore, the microcontroller is quick enough to control the load and obtain a fast enough transient response to at least the order of microseconds since one clock cycle is $31 \mathrm{~ns}$ with this microcontroller. There is room for improvement with the code to make it faster but even written poorly, it will perform on a microsecond scale. An impulse was programmed to the order of 100ns and the current waveform did not even move and was therefore stretched to $10 \mathrm{~ms}$. 
Somewhere in the op-amp loop, there are one or multiple components slowing down the turn-on and turn-off time of the current. The MOSFET has a turn-on time of $77 \mathrm{~ns}$ and the current sense resistor should be just as fast because it has no added circuitry that controls how it turns on and turns off. The only remaining parts that could slow down that current would be the op-amp or the control loop. As seen in Figure 6.11, the waveform shows a rise time of nearly $5 \mu$ s with a capacitive load of $10 \mathrm{nF}$. The reason for choosing this op-amp in the first place was its ability to drive large capacitive loads that others were unstable driving. Without knowing the specific load capacitance this op-amp is driving, it would not be unreasonable to think that the op-amp could be one portion of this circuit slowing down the rise time of the current. Further investigation would need to be performed to verify these conclusions.

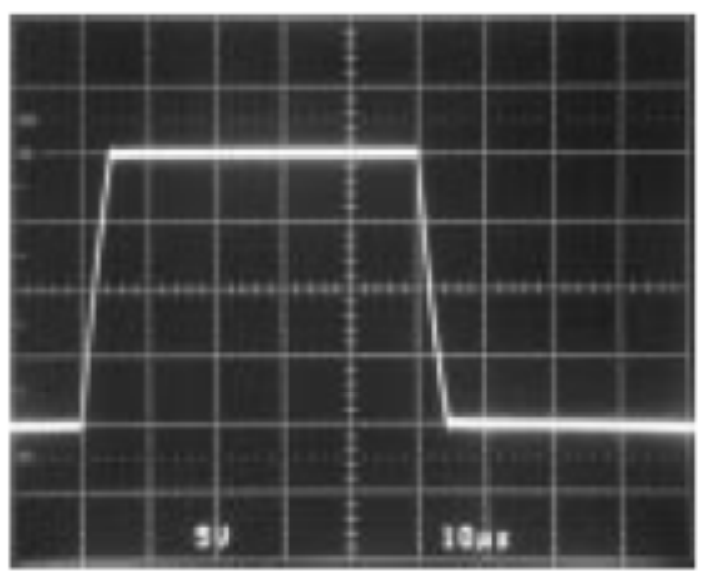

Figure 6.11: Linear Technology LT1351 op-amp, large-signal transient waveform from data sheet $-A_{V}=1$, $\mathrm{C}_{\mathrm{L}}=10,000 \mathrm{pF}[14]$ 


\section{Conclusion}

Electronic loads are very common test instruments especially in power supply design but they are usually large, bulky, and expensive. The digitally controlled electronic load discussed in this paper is designed to overcome those obstacles and it accomplishes all of the defined goals. In general, the load operates as expected which demonstrates that the concept works; however, there is always room for improvements. The overarching goal for this load was that it could operate modularly with a very small footprint and that was accomplished.

Some areas to improve would be the cabling attaching the MOSFET and current sense resistor needs to be the same length. The current sense resistor needs to have an accurate voltage measurement fed back to the main op-amp, U4. A high impedance device like a differential instrumentation amplifier could be used to take that accurate voltage measurement.

One limitation noticed in this design during testing that would be worth investigating in a future design is the minimum voltage needed on the SUT to make the load function. In the proposed load, low $\mathrm{V}_{\mathrm{DS}}$ voltages would limit the amount of drain current available to the MOSFET. Most electronic loads have a minimum input voltage value that was noticed in the load as well. A SUT voltage of $3.3 \mathrm{~V}$ did not prevent the load from operating but limited the amount of current the load could sink. The reason for this limitation is that the MOSFET acts as a shunt resistor, the harder it turns on, the lower the resistance. At some point, the MOSFET cannot lower the resistance anymore 
and goes into saturation mode which has a minimum resistance of $\mathrm{R}_{\mathrm{DS}-\mathrm{ON}}$ and therefore the lowest resistance obtainable by this MOSFET [15].

An improvement that could be made to this load in a future design would be to lower the minimum voltage specification. Using ideas from [15] would be a start to lowering that voltage. The linear boost supply is a common idea that has been proposed in other papers as well. It would seem that using a linear boost supply could cause other complications in this design. One such challenge would be that each module might need one of these supplies and since they would not need to be used in every instance, they would need to be turned on and off when appropriate. There would also be the need to investigate how the linear boost supplies function in the sense that one only wants to pull current from the SUT and not from the boost supply. If current is pulled from the boost supply as well, it would need to be accounted for in the maximum current rating.

Another way to improve the issue with minimum voltage level would be to add MOSFETs in parallel. Just like the modules, the main MOSFETs could be paralleled up per module to lower the $\mathrm{R}_{\mathrm{DS}-\mathrm{ON}}$ value while allowing each module to handle more power. Unlike [15], the goal would be to allow the load to fully operate at a minimum voltage of maybe $0.5 \mathrm{~V}$. This could easily be achievable by paralleling the main MOSFET.

As reported in this thesis, the proposed design was able to have three modules placed in parallel and share the current from the SUT. The design was built with a small footprint that could shrink even more in a full production scale. This design also accomplished the task of controlling the load feature from a microcontroller that allows for easy field modifications if testing parameters need to be changed. 


\section{BIBLIOGRAPHY}

B\&K Precision Corporation, "Support Downloads," 2009. [Online]. Available: 1] http://www.bkprecision.com/support/downloads/application_notes/DC_Electronic_Lo ad_Application_Note.pdf. [Accessed 7 November 2011].

B\&K Precision Corporation, "Electronic Test Instruments," 6 October 2006.

2] [Online]. Available:

http://bkprecision.typepad.com/my_weblog/2006/10/600w_programmab.html. [Accessed 18 October 2011].

J. C. Rosas-Caro, F. Z. Peng, H. Cha and C. Rogers, "Z-source converter based

3] zero voltage electronic load," Power Electronics Specialist Conference, pp. 27642770, 2008.

S. Mishra and X. Zhou, "Design Considerations for a Low-Voltage High-

4] Current Redundant Parallel Voltage Regulator Module System," Industrial Electronics, vol. 58, no. 4, pp. 1330-1338, 2011.

M. Kazerani, "A High-Performance Controllable DC Load," Industrial 5] Electronics, pp. 1015-1020, 2007.

L. Haiying, W. Jing, H. Songling and Z. Wei, "Design of the Feedback Type 6] DC Electronic Load Hardware Circuit Using IPM," Electrical and Computer Engineering, pp. 156-159, 2011.

S. Upadhyay, S. Mishra and A. Joshi, "A Switching Converter Based 
7] Electronic Load," Applied Power Electronics Conference and Exposition, pp. 13941397, 2011.

B\&K Precision Corporation, "150 W DC Electronic Load," November 2008.

8] [Online]. Available: http://www.bkprecision.com/products/model/8540/150-w-dcelectronic-load.html. [Accessed 7 November 2011].

J. March, "Modular Electornic Load," California Polytechnic State University, 9] San Luis Obispo, 2010.

STMicroelectronics, "STW26NM50," 2011. [Online]. Available:

1 http://www.st.com/internet/com/TECHNICAL_RESOURCES/TECHNICAL_LITER

0] ATURE/DATASHEET/CD00002680.pdf. [Accessed 25 May 2011].

Atmel Corporation, "XMEGA-A1 Xplained," 2011. [Online]. Available:

1 http://www.atmel.com/dyn/resources/prod_documents/doc8370.pdf. [Accessed 1611 1] 2011].

Atmel Corporation, "ATxmega128A1," 2011. [Online]. Available:

1 http://www.atmel.com/dyn/products/product_parameters.asp?category_id=163\&famil

2] y_id=607\&subfamily_id=1965\&part_id=4298\&ListAllAttributes=1. [Accessed 1611 2011].

National Semiconductor, "Instrumentation Amplifier," March 1969. [Online].

1 Available: http://www.national.com/ms/LB/LB-1.pdf. [Accessed 1811 2011].

3]

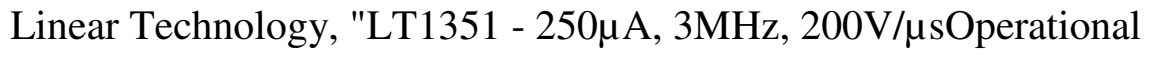

1 Amplifier," 2011. [Online]. Available: 
4] http://cds.linear.com/docs/Datasheet/1351fa.pdf. [Accessed 2211 2011].

Agilent Technologies, "Technical Support - Document Library," 07 June 2001.

1 [Online]. Available: http://cp.literature.agilent.com/litweb/pdf/5968-6360E.pdf.

5] [Accessed 14 October 2011]. 


\section{Appendices}

The following sections are a collection of additional information that may be useful while reading this report.

\section{a) Appendix A}

This is the full code set programmed onto the load's microcontroller.

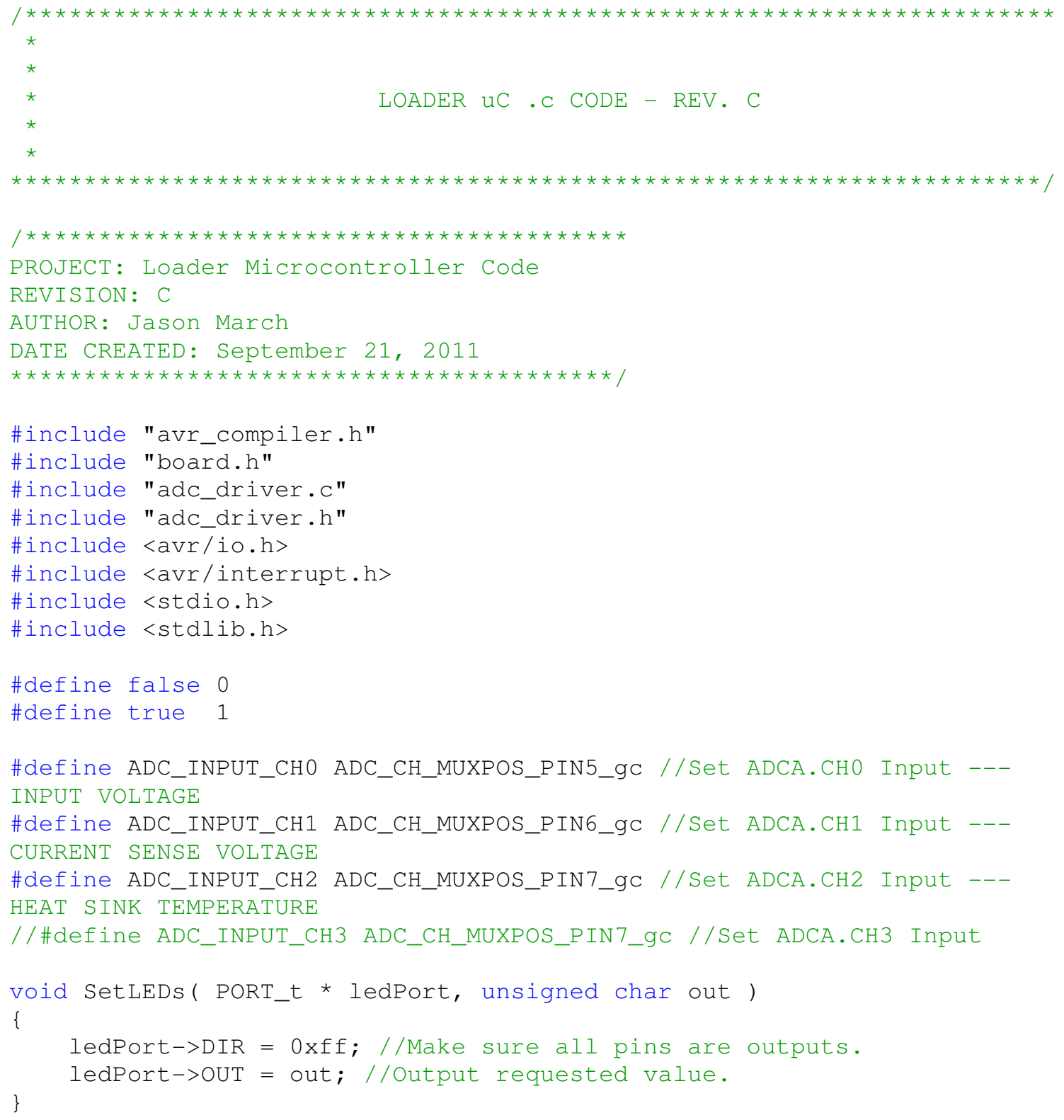




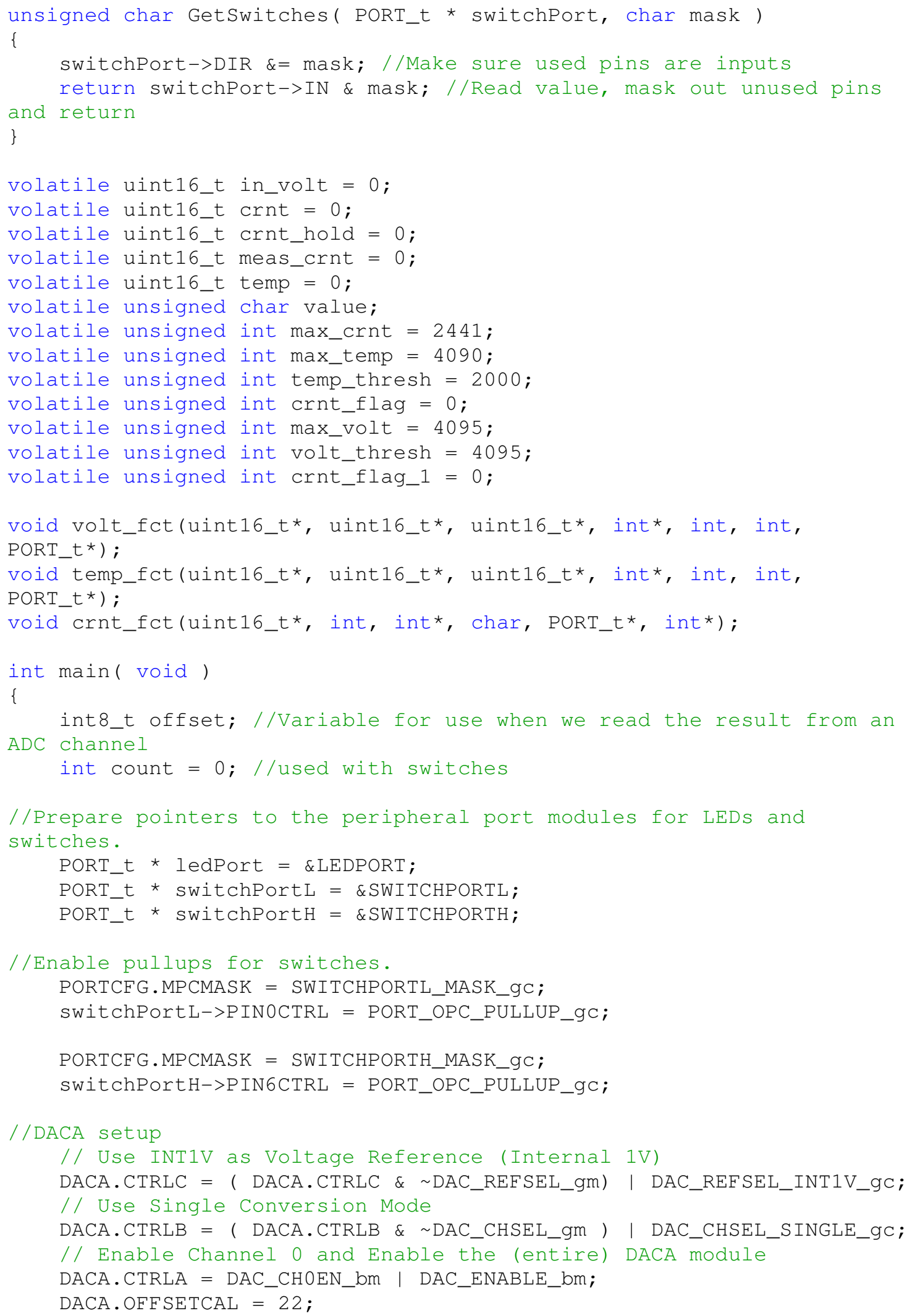




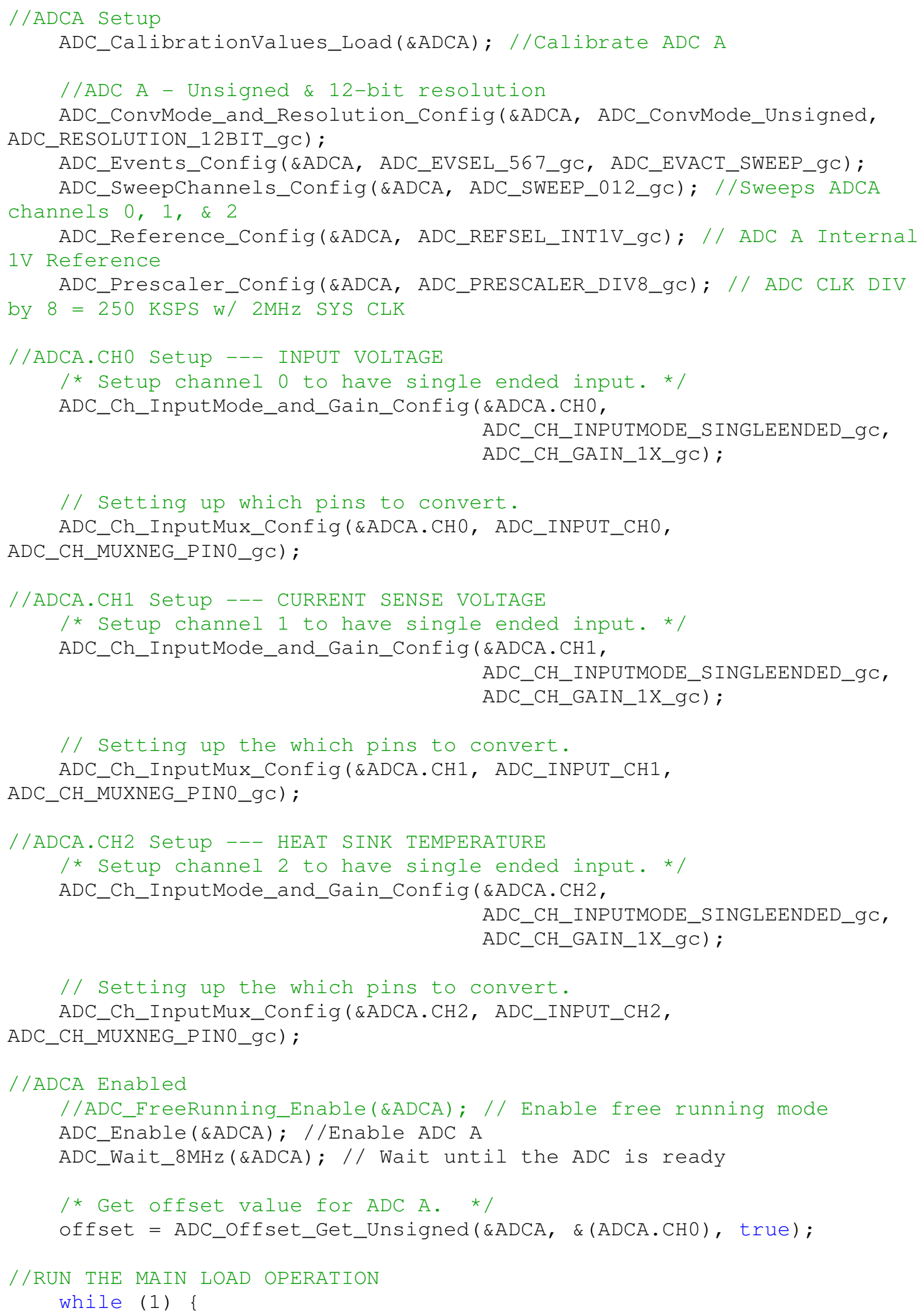


while(!ADC_Ch_Conversion_Complete(\&ADCA.CHO)); // Wait for the conversion to complete

in_volt = ADC_ResultCh_GetWord(\&ADCA.CHO); //Get the result

ADC_Ch_Conversion_Start(\&ADCA.CH1); //Start a single conversion while(!ADC_Ch_Conversion_Complete(\&ADCA.CH1)); //Wait for the conversion to complete meas_crnt $=$ ADC_ResultCh_GetWord (\&ADCA.CH1); / / Get the result

ADC_Ch_Conversion_Start(\&ADCA.CH2); //Start a single conversion while(!ADC_Ch_Conversion_Complete(\&ADCA.CH2)); //Wait for the conversion to complete temp = ADC_ResultCh_GetWord (\&ADCA.CH2); //Get the result

volt_fct(\&in_volt, \&crnt, \&crnt_hold, \&crnt_flag_1, max_volt, volt_thresh, ledPort);

temp_fct (\&temp, \&crnt, \&crnt_hold, \&crnt_flag, max_temp, temp_thresh, ledPort);

value = READ_SWITCHES;

crnt_fct(\&crnt, max_crnt, \&crnt_flag, value, ledPort, \&count);

//write output to DAC

while ( (DACA.STATUS \& DAC_CHODRE_bm) == false ) \{

\}

DACA.CHODATA = crnt;

\}

void volt_fct(uint16_t* in_volt, uint16_t* crnt, uint16_t* crnt_hold, int* crnt_flag_1, int max_volt, int volt_thresh, PORT_t* ledPort) \{

if ( (*in_volt $>=$ max_volt) \&\& (*crnt_flag_1 $==0) \quad$ )

*crnt_hold $={ }^{*}$ crnt;

${ }^{*}$ crnt_flag_1 $=1$;

${ }^{*}$ crnt $=0$;

SetLEDs ( ledPort, OxAA);

\}

if $($ (*in_volt < volt_thresh) \&\& (*crnt_flag_1 $==1) \quad\{$

${ }^{*}$ crnt_flag_1 $=0$;

${ }^{*}$ crnt $={ }^{*}$ crnt_hold;

SetLEDs ( ledPort, $0 \times 55$ );

\}

\}

void temp_fct(uint16_t* temp, uint16_t* crnt, uint16_t* crnt_hold, int* crnt_flag, int max_temp, int temp_thresh, PORT_t* ledPort) \{

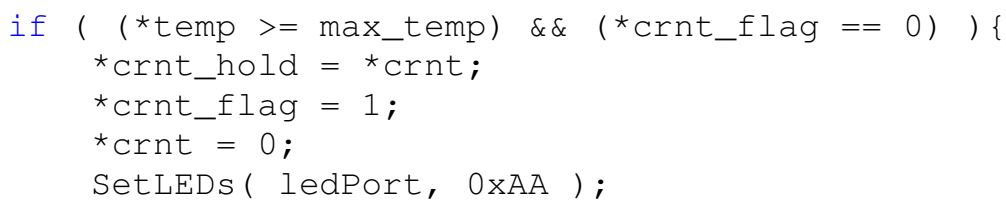




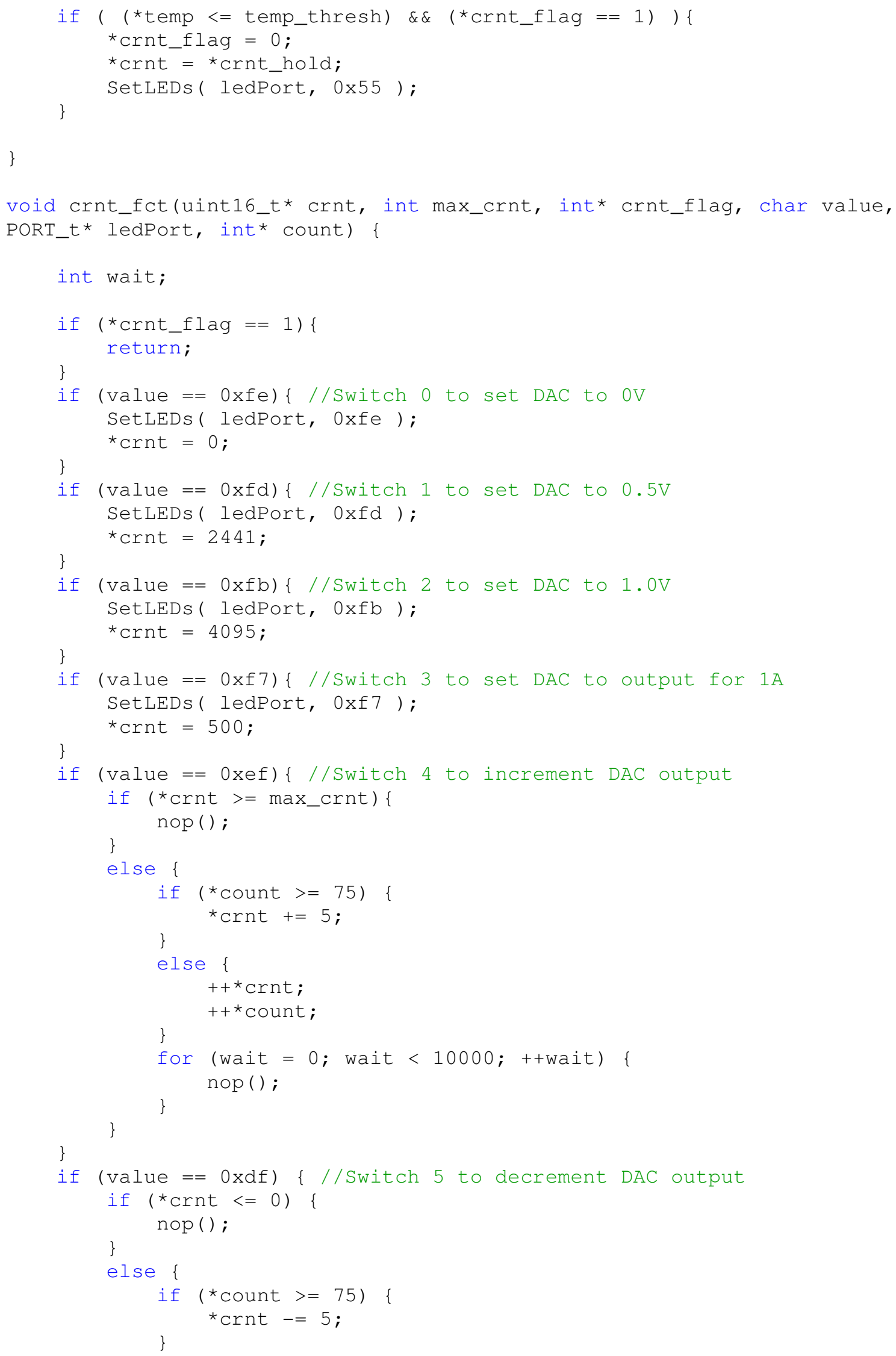




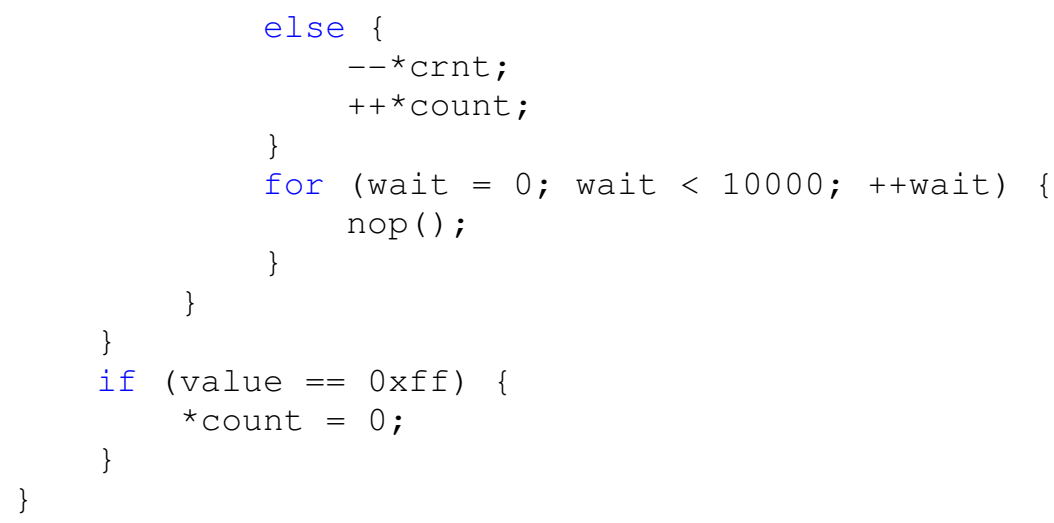




\section{b) Appendix B}

Table 9-1 is the bill of materials for the proposed electronic load.

Table 9-1: Bill of Materials

\begin{tabular}{|c|c|c|c|}
\hline $\begin{array}{c}\text { Schematic } \\
\text { Number }\end{array}$ & Quantity & Digi-key Part Number & Description \\
\hline M7 & 3 & IRFP260NPBF-ND & N-Ch., 200V, 40mOhm, 50A, 300W \\
\hline R3 & 3 & MP930-0.10F-ND & $0.1 \mathrm{Ohm}, 30 \mathrm{~W}, 1 \%$, isolated \\
\hline R5/R9 & 3 & RHM10.0KCRCT-ND & $10 \mathrm{kOhm}$, thick film, $1 / 8 \mathrm{~W}, 1 \%$ \\
\hline R4 & 3 & RHM1.00KAECT-ND & $1 \mathrm{kOhm}$, thick film, $1 / 4 \mathrm{~W}, 1 \%$ \\
\hline $\mathrm{C} 2 / \mathrm{C} 3$ & 3 & 478-3755-1-ND & $.1 \mathrm{uF}, 25 \mathrm{~V}, 10 \%$, Ceramic, X7R \\
\hline U4 & 3 & LT1351CS8-ND & $250 \mathrm{~mA}, 3 \mathrm{MHz}, 200 \mathrm{~V} / \mathrm{ms}$ \\
\hline $\mathbf{R 8}$ & 3 & 541-590KAFCT-ND & RES 590K OHM 1W 1\% 2512 SMD \\
\hline Vtemp & 3 & LM35DT-ND & 4-30V, 0-100C, voltage \\
\hline Microcontroller & 1 & ATAVRXPLAIN-ND & KIT EVAL FOR ATXMEGA128A1 \\
\hline U1 & 1 & MC7812BDTRKGOSCT-ND & $V o=12 V, I o=1 A, V i<35 V, V d=2 V$ \\
\hline U2 & 1 & MC7912ACTGOS-ND & $\mathrm{Vo}=-12 \mathrm{~V}, \mathrm{Io}=500 \mathrm{~mA}, \mathrm{Vi}>-35 \mathrm{~V}, \mathrm{Vd}=1.1 \mathrm{~V}$ \\
\hline D1, D2 & 2 & MSS1P5-M3/89AGICT-ND & $V f=680 m V, V r=50 V, 1 A$ \\
\hline C1, C2 & 2 & PCE4444CT-ND & 220UF 35V ELECT 80mOhm +/-20\% \\
\hline $\mathrm{C} 15, \mathrm{C} 16$ & 2 & 587-1962-1-ND & CER, 4.7UF, 50V, X5R, 10\% \\
\hline C3, C5 & 2 & 718-1141-1-ND & Tant, .33u, 35V, 13mohm \\
\hline C4, C6 & 2 & 478-2412-1-ND & Tant, 1u, 35V, 2ohm \\
\hline Vin connector & 1 & CP-102A-ND & Male, $2.1 \mathrm{~mm}$ ID, $5.5 \mathrm{~mm}$ OD \\
\hline J1 - Male & 1 & 1-794628-6-ND & Header, 16 pos, $3 \mathrm{~mm}$, Gold CNT \\
\hline J1 - Female & 1 & A30300-ND & Receptacle, 3mm, 16 pos, Blk \\
\hline Pins & 16 & A30305-ND & Socket, Crimp, 20-24 AWG, Tin \\
\hline J2 - Male & 3 & WM1041-ND & CONN HEADER 2POS .093 VERT TIN \\
\hline J2 - Female & 3 & WM1671-ND & CONN RECEPTACLE 2POS .093 \\
\hline Pins & 6 & WM1101-ND & 14-20 AWG, Tin, Female \\
\hline J3 - Male & 3 & A1216-ND & Header, 8 pos, Tin, \\
\hline J3 - Female & 3 & A1207-ND & Receptacle, 8 pos \\
\hline Pins & 24 & A1421-ND & Socket, Crimp, 14-20 AWG, Tin \\
\hline J4 - Male & 3 & A32484-ND & 16 pins, 2 rows, right angle \\
\hline J4 - Female & 3 & A25579-ND & 16 pins, 2 rows, crimp \\
\hline Pins & 48 & A100828CT-ND & 16-20 AWG, Tin \\
\hline
\end{tabular}

